\title{
LA DEMOCRACIA A PROFUNDIZAR Y EXTENDER
}

\author{
Demetrio Velasco Criado
}

\section{Resumen}

\section{La democracia a profundizar y extender}

El título que encabeza estas páginas plantea, en sí mismo, varias cuestiones, ya que extender la democracia no sólo no equivale a profundizar en ella, sino que, como ocurre en la realidad, puede suceder lo contrario. Se trata, pues, de ver cómo se compatibilizan ambos objetivos.

\section{1. ¿Qué democracia debemos profundizar y extender?}

La democracia es, a la vez, e indisolublemente, una construcción ética y política de la convivencia social y una obra de ingeniería institucional y procedimental. Es imprescindible tener en cuenta ambas dimensiones. Pero, a la hora de poner en práctica el proyecto democrático, se nos plantean serias dificultades que tienen que ver tanto con la naturaleza institucional de la sociedad democrática (paradojas lógicas y perversiones prácticas), como con la naturaleza de los individuos que componen dicha sociedad (calidad de la ciudadanía).

\subsection{Lecciones de la historia reciente}

Las dos tradiciones democráticas más importantes (americana y francesa) han intentado solventar estas dificultades, que se resumen en cómo lograr que los individuos trasciendan sus pasiones e intereses egoístas y se comporten con la moralidad que exige la vida democrática.

\subsection{Profundizar y extender la democracia, hoy}

La enorme y creciente complejidad de nuestras sociedades (subsistemas, sectores sociales y niveles de gobierno, con lógicas diferentes) hace especialmente problemática la plasmación del proyecto democrático (cohesión, gobernabilidad, 
participación) y, sobre todo, obliga a tener en cuenta algunos retos nuevos (globalización, multiculturalismo y nuevas tecnologías de la información), que exigen imaginación y decisión democráticas, también renovadas.

\subsection{Aprendiendo de una discusión}

Liberales y comunitaristas acentúan aspectos diferentes de la cuestión democrática que hay que tener en cuenta.

\section{La democracia directa a debate}

Se suele pensar que la democracia directa es la solución a todos los problemas democráticos. Sin embargo, su puesta en práctica plantea serios problemas que es imprescindible tener en cuenta.

\section{3. ¿La democracia electrónica o el sondeo deliberativo, como solución?}

Las nuevas tecnologías de la comunicación son un instrumento extraordinario, cuyas posibilidades hay que utilizar para la causa de la democracia. Pero, no hay que olvidar que no existen soluciones «técnicas» para los problemas democráticos.

\section{4. ¿Qué hacer?}

Aunque tengamos más preguntas que respuestas, parece claro que debemos empezar por reafirmar la fe democrática que tanta evidencia empírica ha podido debilitar o apagar. Debemos recuperar la base moral de la democracia y apostar por un proyecto de democracia global. Para ello, es preciso hacer frente a las fuentes más importantes de «nautonomía», como son el capitalismo neoliberal, los etnocentrismos excluyentes y el uso antidemocrático de los nuevas tecnologías de la información.

\subsection{Neoliberalismo (capitalismo neoliberal) y negación de la autonomía} democrática.

4.2. Pluriculturalismo y «políticas de la identidad». Nacionalismo etnocultural versus democracia.

4.3. El control y la manipulación de la información, del conocimiento y de la opinión pública. Papel de los Medios de comunicación social: ¿instrumentos o mediaciones?

\section{La ciudadanía democrática: objetivo de la comunidad política democrática}

Debemos recuperar el sentido revolucionario de la ciudadanía moderna y afirmar el proyecto de comunidades políticas inclusivas, en las que la ciudadanía no quede hipotecada ni por el individualismo liberal, desigualitario e injusto, ni 
por el colectivismo excluyente de las políticas de identidad, ni por una sociedad de la información que imposibilita a la ciudadanía el control cognitivo de la misma. La ciudadanía democrática debe ser la forma en la que los seres humanos vamos haciendo realidad el momento histórico del «altruismo universal», dando fiel cumplimiento de la figura del «reconocimiento».

La educación cívica y la participación responsable, como tareas urgentes.

El título que encabeza estas páginas expresa una convicción que estoy seguro que compartimos quienes nos tenemos por demócratas progresistas: «el remedio a los males de la democracia es más democracia». Pero parece que dicho título tiene también en cuenta la advertencia de Tocqueville: «uno de los mayores peligros para la democracia viene del exceso de democracia». Obviamente, se trata de «determinar» la democracia que queremos profundizar y extender. No se trata de cualquier democracia.

De hecho, se ha dado una gran extensión de la democracia en los últimos tiempos. Son cada vez más los países que apuestan por regímenes democráticos y la democracia se convierte en una especie de seña de identidad obligada por el contexto internacional ${ }^{1}$. Y, sin embargo, abundan los diagnósticos de los analistas que nos señalan que vivimos malos tiempos para la democracia y que se aproximan tiempos aún peores ${ }^{2}$.

1 J. M. Colomer, en artículo titulado «Democratizaciones estratégicas», publicado en El País, 8/XI/1999, escribía: "Nunca había habido antes un conjunto de cambios democratizadores tan amplio y tan rápido, con una tasa tan alta de éxito y con un nivel tan bajo de conflicto violento. Desde finales de los años ochenta un total de 28 países antes dominados por el partido comunista han experimentado importantes transformaciones políticas y económicas... Con la caída de los regímenes comunistas en Europa oriental culminó la tercera ola de democratización, que había empezado a mediados de los setenta en Europa del Sur y se extendió luego a América Latina».

2 Ralph DAHRENDORF, en un artículo titulado «Despues de la democracia, ¿qué?», llegaba a afirmar que son cada vez más quienes cuestionan la democracia. «De hecho, no es demasiado exagerado decir que la democracia parlamentaria tal y como la conocemos está en las últimas... Fundamentalismos, retornos de gobiernos autoritarios, declive del Estado nacional (fuera del cual dice no hay ninguna democracia digna de este nombre)...». El País. 2/II/200; el mismo Dahrendorf manifiesta su escepticismo ante la posibilidad de poder aplicar las ideas y la práctica de un gobierno democrático a las organizaciones, procesos e instituciones internacionales, incluida la Unión Europea. Claves de Razón Práctica. N. ${ }^{\circ}$ 97, pp. 8-9. John MARKOFF, en su libro Olas de democracia. Movimientos sociales y cambio político, al referirse a la nueva ola de democratización de los años noventa, 
Esta aparente paradoja de que la democracia se extienda, precisamente, en un momento y en unas condiciones que la hacen cada vez más difícil, nos lleva a plantearnos la cuestión del futuro de la democracia y de su calidad. En efecto, en un mundo que cambia vertiginosamente, la democracia se enfrenta a retos y amenazas que, en su mayor parte, se han agravado a causa de los cambios producidos por la globalización, el multiculturalismo y la sociedad de la información ${ }^{3}$.

\section{1. ¿Qué democracia debemos profundizar y extender?}

La democracia que debemos profundizar y extender creo que tiene que ser una democracia que sea, a la vez, una construcción ética y política de la convivencia entre seres humanos libres e iguales, que ejercen su ciudadanía libre y solidariamente, y una obra de ingeniería institucional y procedimental, que genere instituciones, normas y procedimientos para solucionar los numerosos problemas de sociedades tan complejas, pluralistas y fragmentadas como las nuestras. Ambas dimensiones son imprescindibles y están indisolublemente unidas.

y en un apartado que titula «Pero, democracia o... democratización», se pregunta si de verdad estamos asistiendo a una democratización o, más bien, a una instrumentalización de la democracia por parte de los grandes poderes para legitimar procesos que, con frecuencia, son seudodemocráticos o claramente autocráticos. Coincide en que estamos en tiempos nada fáciles para la democracia. Véase op. cit. Tecnos, Madrid. 1998, pp.

${ }^{3}$ F. VALLESPín presenta una síntesis de esas amenazas y problemas: 1. El problema de la mediación política (partitocracia y corporativización) (¿hasta cuándo será posible mantener la ficción de una democracia apoyada sobre la igualdad política de todos los ciudadanos frente a la efectiva y creciente organización corporativa de los intereses?); 2. El problema de la especialización y complejidad de la vida política (la tecnocracia) (¿una nueva forma de tutelaje, como plantea Dahl?); 3. El problema de la publicidad y transparencia política (la manipulación política) («democracia mediática» —A. Minc—; «de audiencia» -Manin-, «videopolítica»-Sartori-); 4. El problema de la colonización de la política por la economía (¿cuál es el umbral mínimo de desigualdad para una realización consecuente del principio democrático?); 5. El problema de las políticas de identidad y sus desafíos (no hay una clara solución de ingeniería constitucional); 6, El problema de la «calidad» de la democracia (¿democracias avanzadas o democracias «defectuosas»?). Véase Claves de Razón Práctica. N. ${ }^{\circ}$ 97. pp 5-6.

Como ejemplo de la importancia de las instituciones y de los procedimientos, véase la obra de J. PH. HeurTin. L'espace public parlementaire. Essai sur les raisons du législateur. PUF. Paris. 1999. Dice así el autor: «la arquitectura (se refiere a la forma histórica en que se ha realizado el Parlamento, en diversos lugares y contextos: anfiteatro, cara a cara, tribuna, sedes de partidos, etc.) no es una prótesis, sino que constituye un medio cognitivo, que prolonga las capacidades individuales». Es, asimismo, conocida la obra de Habermas y su tratamiento de la «reflexión y la normatividad». 
No creo que haya dificultad en ponernos de acuerdo en aceptar una definición de la democracia, como la que ofrece, por ejemplo, R. Dahl en su última obra: La democracia una guía para los ciudadanos. Dahl subraya que, dada la enorme polisemia que el término democracia tiene, hay cinco criterios que cree imprescindibles para su adecuada definición, porque, si faltara alguno de ellos, los miembros de la sociedad ya no serían iguales políticamente, algo imprescindible para hablar de democracia. Estos cinco criterios son: participación efectiva («todos los miembros de la asociación, deben tener oportunidades iguales y efectivas para hacer que sus puntos de vista sobre cómo haya de ser la política sean conocidos por los otros miembros»), igualdad de voto («a la hora de decidir, todo miembro debe tener una igual y efectiva oportunidad de votar, y todos los votos deben contarse como iguales»), comprensión ilustrada («dentro de los límites razonables en lo relativo al tiempo, todo miembro debe tener oportunidades iguales y efectivas para instruirse sobre las políticas alternativas relevantes y sus consecuencias posibles»), control de la agenda («los miembros deben tener la oportunidad exclusiva de decidir cómo y, si así lo eligen, qué asuntos deben ser incorporados a la agenda. De esta forma, el proceso democrático exigido por los tres criterios precedentes no se cierra nunca. Las políticas de la asociación están siempre abiertas a cambios introducidos por sus miembros, si éstos así lo deciden»), inclusión de adultos («todos o, al menos, la mayoría de los adultos que son residentes permanentes, deben tener los plenos derechos de ciudadanía que están implícitos en los cuatro criterios anteriores. Antes del siglo Xx, este criterio era inaceptable para la mayoría de los defensores de la democracia. Para justificarlo, habremos de examinar por qué debemos tratar a las otras personas como a nuestros iguales políticos») ${ }^{4}$

Como es obvio, para aplicar estos criterios básicos se hace imprescindible la creación de instituciones que los hagan viables y plausibles. Este es, seguramente, el nudo gordiano de la profundización y extensión democráticas. Cuestiones como el sistema de la representación política, el modelo de la creación de la opinión pública o la forma de ejercicio de la ciudadanía democrática, son instituciones que necesitan

4 R. DAhl. La democracia. Una guía para los ciudadanos. Taurus. Madrid. 1999, pp. 47-48. La obra de R. Dahl me parece especialmente significativa por la larga y rica trayectoria intelectual del autor, así como por la evolución que ha tenido en su pensamiento. El elitista de antes es hoy un defensor de la democracia participativa. El itinerario de Dahl es un buen ejemplo de las dudas que puede suscitar la búsqueda del sistema democrático adecuado. 
una atención preferente para quien pretenda hacer posible una sociedad democrática 5 .

Es importante que asumamos con convicción que la democracia, definida con estos criterios ideales, es posible y que es posible, porque creemos que todos los seres humanos somos intrínsecamente iguales y capaces de decidir sobre lo que pensamos que es mejor para nosotros y para los demás, y que, por tanto, descartamos cualquier otra alternativa que no acepte estas premisas. Yo no me canso de subrayar que, en esta creencia, bien fundamentada, está el subsuelo en el que pueden germinar y florecer con fuerza los usos democráticos. Como veremos, los abusos, perversiones y tendencias suicidas de las instituciones democráticas tienen su raíz más profunda en una negación práctica (a veces, también teórica) y sistemática de dicha creencia. No se trata de argumentar ahora, como, por ejemplo, hace Dahl ${ }^{6}$, sobre la inconsistencia de la teoría del tutelaje, pero sí, de recordarnos que una cosa es la competencia técnica y otra la idoneidad moral para ejercer la responsabilidad política. Todos los seres humanos tenemos idoneidad moral para «ser sujetos», para ser autónomos. Esta es la gran convicción de la tradición revolucionaria, en la que nace el ideal democrático. Desgraciadamente, no faltan, también entre nosotros, expresiones de particularismos premodernos y de individualismos antidemocráticos, que niegan la igualdad política y los criterios arriba mencionados... (un ejemplo reciente es la justificación de un censo excluyente por razones etnoculturales).

$\mathrm{Si}$ recalco esto es porque, a pesar de que hay muchas razones para ver, en la democracia, el más beneficioso de los regímenes políticos, tanto por los males que evita (autocracias y tiranías con todas sus corrupciones) como por los bienes que garantiza (derechos humanos en todas sus dimensiones $)^{7}$, hay, también, demasiadas evidencias empíricas para cuestionarnos, una y otra vez, nuestras creencias democráticas. Y no me refiero solamente a las «evidencias empíricas» que, para algunos autores, han generado lo que se llama «malestar democrático»o las que

5 El mismo Dahl enumera las instituciones requeridas por una democracia a gran escala: cargos públicos electos; elecciones libres, imparciales y frecuentes; libertad de expresión; fuentes alternativas de información; autonomía de las asociaciones y ciudadanía inclusiva. Véase op. cit., pp. 99 ss.

${ }^{6}$ R. DAHL. La democracia y sus críticos. Paidós. Barcelona. 1992. pp. 67 ss.

7 Estas han sido las tesis de numerosos autores, desde Tocqueville a A. Sen. Aunque, como dice Colomer, en el caso de las democratizaciones del los países del Este, «no hay relación determinista entre desarrollo socioeconómico y la democratización política, en contraste con la tesis estructuralista difundida por la sociología algunos decenios atrás». Véase Ibid. 
instrumentan los neoconservadores y neoliberales para justificar modelos de democracia lejanos al que acabamos de definir, como el modelo de «democracia legal» (argumentando que el verdadero liberalismo, el angloescocés ha sido pervertido por el modelo «liberal-socialista», como lo muestra el fracaso del EBK) ${ }^{8}$, sino, también, a las dificultades que se generan, al aplicar concretamente el ideal democrático y sus cinco criterios básicos.

En efecto, cuando se trata de pasar a la aplicación práctica de estos criterios, resulta que no sólo es muy difícil, sino que, en algunas circunstancias y contextos, es imposible o incluso indeseable. La evidencia empírica nos muestra que no siempre se logra profundizar y extender la democracia antes definida, con más participación, con más información; con más control sobre la agenda, con un mayor número de participantes, en una palabra, con más democracia directa ${ }^{9}$.

La razón fundamental que explica esta decepcionante realidad no es sólo institucional o estructural (desde Aristóteles a nuestros días, pasando por Montesquieu se ha reflexionado acertadamente sobre las formas de gobierno...), aunque la referencia a la complejidad de nuestras sociedades es fundamental al respecto, sino que hay que buscarla, también, en el comportamiento de los individuos y grupos humanos que conforman nuestras sociedades. No todos los individuos o grupos humanos, ni en todos los momentos, se comportan como sujetos capaces e idóneos en la consecución de los fines democráticos. Es el problema de la calidad de la ciudadanía y de la generación de los «recursos morales» que son imprescindibles para la construcción de una sociedad democrática.

Si hay, en mi opinión, una razón última que explica la decepcionante realidad de muchas de nuestras democracias, ésta es la conocida como «espíritu del capitalismo», entendiéndolo, sobre todo, como «individualismo posesivo». Esta evidencia empírica es, para mí, el subsuelo que ha configurado de forma decisiva la mentalidad de las sociedades construidas según el paradigma del «materialismo histórico reaccionario». En él, han germinado no sólo los abusos y perversiones de las formas políticas del liberalismo, sino que, también, se han asentado los usos, procedimientos y actitudes que se han convertido en dominantes en nuestras sociedades democráticas ${ }^{10}$.

8 Véase la obra de D. Held, Modelos de democracia. Alianza Universidad. Madrid 1992.

9 Véase la obra de Yannis PAPAdopoulos, Démocratie directe. Ed. Economica. Paris. 1998. En esta obra el autor hace un riguroso análisis de las virtualidades y deficiencias de la democracia directa. Más adelante, haré algunas referencias a esta obra.

10 Creo que hay que completar y corregir la visión weberiana del «espíritu del capitalismo» con las interpretaciones, para mí, más pertinentes de Nietzsche o Leo Köfler. Para ver 
No es este el momento de hacer una justificación histórico-ideológica de esta trascendente afirmación. Me remito al análisis de autores, como Offe y Preuss, que nos describen la trayectoria histórica de los modelos democráticos más relevantes que han existido y que explican el porqué nuestras democracias están donde están, a la vez que se preguntan cómo podemos y debemos profundizar en ellas. Para ellos, el relativo éxito de los modelos democráticos se ha debido a que han sabido, precisamente, tener en cuenta esta evidencia empírica del individualismo posesivo y de los particularismos excluyentes que lo han acompañado, con el objetivo de domesticarlo y humanizarlo a través de las instituciones democráticas y de la educación en los principios e ideales que las inspiran. El desconocimiento de este principio, o la connivencia cómplice con él, estaría, por el contrario, en el origen del fracaso de las sociedades democráticas ${ }^{11}$.

No es, pues, tanto problema el definir qué es la democracia, como el encontrar la mejor forma de encarnarla en cada contexto concreto. El problema del cómo es clave para lograr nuestro objetivo. Por eso, comenzaré por echar una mirada retrospectiva al cómo se ha respondido a este reto en la historia reciente de nuestras sociedades occidentales para pasar, más tarde, a ver cómo podemos y debemos seguir haciéndo-

cómo este individualismo posesivo ha sido determinante en la construcción de las instituciones democráticas y en la mentalidad moderna, véase la obra de R. Polin, L'esprit totalitaire. Sirey, Paris, 1977. En este momento, creo pertinente hacer una referencia a las perversiones democráticas, del sistema de representación política, en general y de los partidos políticos, en particular, que no han hecho sino agudizarse hasta nuestros días. La representación política ha carecido de la suficiente legitimidad democrática porque ha padecido un proceso de burocratización, oligarquización y colonización por la lógica economicista, que ha terminado por imponer otras formas de legitimidad (técnica, eficacia, neutralidad), que han desplazado a la legitimidad democrática. Un proceso que ha sido colusivo con el de los partidos políticos, que, desde su propia perversión, a través, asimismo, de su burocratización, oligarquización y mercantilización, han creado una actitud de apatía y de malestar cívico, que, además de alejar a los representantes de los representados, ha sustituido a estos últimos por una nutrida clientela, ávida de movilidad social ascendente. La representación política se ha pervertido, además, porque en las modernas «democracias de audiencia» el consenso de los representados ha sido desvirtuado por una instrumentalización y manipulación partidista y oligárquica de los medios de comunicación social. Véase B. MANIN, Los principios del gobierno representativo. Alianza Editorial. Madrid, 1988; A.J. PORRAS NADALES (ed.) El debate sobre la crisis de la representación política. Tecnos, Madrid, 1996; P. Vega García, Legitimidad y representación en la crisis de la democracia actual; Institut de ciences politiques i socials. Barcelona, 1998. Obras de clásicos en el tema, como Pitkin, Fishkin, etc... Como una muestra de la crisis de legitimidad democrática de los partidos políticos, véase el breve artículo de R. VARGAS MACHUCA, «Un modelo vulnerable», El País, 6/II/2000.

${ }^{11}$ Una obra que puede ser útil para ilustrar lo que decimos es la obra de A. PrzeworsKI, Capitalismo y socialdemocracia. Alianza Universidad. Madrid. 1988. 
lo en nuestros días. Esta mirada al pasado que, por otro lado, sigue perpetuándose, nos permitirá abordar nuestra cuestión con la perspectiva necesaria...

\subsection{Lecciones de la historia reciente}

Es sabido que las dos grandes tradiciones democráticas occidentales, la nacida de la revolución americana y la nacida de la revolución francesa, se enfrentaron, desde un comienzo, a un mismo problema: el de la construcción de sociedades democráticas, en las que los individuos vieran reconocidos y garantizados sus derechos y libertades, de forma justa y solidaria. En ambas tradiciones, más allá de sus significativas diferencias, se refleja una nueva forma de autocomprensión de la realidad humana, que no se basa ya en el marco legitimador de la tradición histórica, sino en el de un nuevo orden ontológico revolucionario: el que afirma la dignidad de todos los seres humanos individualmente considerados como sujetos de derechos inalienables. Desde este nuevo orden ontológico, en el que no caben las discriminaciones y los particularismos excluyentes, típicos de la premodernidad, se proyecta un ideal universalista, de carácter democrático, que quedará reflejado en las Grandes Declaraciones de Derechos que se han ido sucediendo a lo largo de la historia ${ }^{12}$.

Bastaría una lectura breve de la Declaración de Derechos del Buen Pueblo de Virginia (1776) o de la Declaración de los Derechos del Hombre y del Ciudadano (1789) para ver cómo, en la búsqueda por lograr alcanzar este ideal universalista, no sólo se confió en el carácter performativo de las mismas declaraciones, sino que se arbitraron fórmulas políticas y jurídicas, instituciones y procedimientos, que fueran capaces de articular y hacer plausibles tanto la afirmación de los derechos individuales como del bien común. C. Offe y U. Preuss han explicado de forma magistral cómo ambas tradiciones democráticas, la americana y la francesa, buscaron realizar sus respectivos modelos de sociedades democráticas ${ }^{13}$. Erigir las instituciones democráticas adecuadas y promover los recursos morales necesarios para que el ejercicio de los derechos y libertades individuales o particulares no pongan

12 Véase D. Velasco. «Los antecedentes histórico-ideológicos de la Declaración Universal de los Derechos del Hombre de 1948», en La Declaración Universal de Derechos Humanos en su cincuenta aniversario. Universidad de Deusto. Bilbao. 1999, pp. 203-308.

13 OfFe, C. y Preuss, U. «Instituciones democráticas y recursos morales», en Isegoría. N. ${ }^{\circ} 2.1990$, pp. $45-74$. 
en peligro la consecución del bien general de la sociedad ha sido el empeño básico de ambas tradiciones. Ahora bien, mientras que los americanos compartían un profundo recelo ante el ejercicio del poder político soberano y un gran escepticismo respecto al papel que los poderes públicos podían desempeñar, a través de la imposición del derecho y de la fuerza legítima, tanto en la moralización de los individuos como en la consecución del bien común, los franceses confiaban casi ciegamente en el potencial transformador de un poder revolucionario, que reflejaba los intereses siempre legítimos y justos de la voluntad general. En manos de este poder, de sus leyes y de su fuerza, estaba el lograr la verdadera socialización de los individuos, que, educados y disciplinados por las instituciones públicas, se convertían en ciudadanos y buscaban el bien común, incluso a costa de sus propios intereses particulares.

Los americanos no contemplaban el ideal de unos ciudadanos guiados por la razón y por la virtud, sino que pensaban en una sociedad integrada por individuos movidos por el propio interés y grupos sociales con proyectos de vida diferentes, según concibieran su propia felicidad. Por eso, en lugar de buscar la unidad del pueblo en una voluntad colectiva de carácter moral, impuesta desde arriba, prefirieron potenciar la diversidad y la fragmentación existentes entre individuos y grupos sociales. Pero, conscientes de la peligrosidad de los intereses egoístas y facciosos de individuos y grupos para la cohesión social, imprescindible en cualquier caso, los americanos apostaron por atajar estos peligros con instituciones, asociaciones y toda una maquinaria constitucional, capaces de socializar e integrar a los individuos y facciones. Offe y Preuss resumen así esta estrategia: «En primer lugar, los intereses controlan a los intereses en el seno de la sociedad de mercado basada en las garantías jurídicas de la propiedad privada y de la libertad de contrato. En segundo lugar, los intereses controlan a los poderes gubernamentales mediante una densa red de derechos democráticos, fundamentalmente las elecciones y la libertad de prensa. En tercer lugar, el poder controla al poder, es decir, los detentadores del poder democrático se controlan recíprocamente a través de unas complejas relaciones de derechos y poderes que se extienden entre instituciones políticas diversas, tales como los estados, el gobierno federal, la presidencia, el Congreso, la Corte Suprema, las fuerzas armadas» ${ }^{14}$.

A pesar de las grandes diferencias entre ambas tradiciones en lo que respecta a la relación entre individuo-sociedad civil-Estado y en la

14 Véase Ibid., pp. 53-54. 
concepción del bien común, comparten, aunque, como ya hemos visto, con diverso alcance y radicalidad, una misma preocupación: la de lograr que los individuos trasciendan sus pasiones e intereses egoístas y se comporten con la moralidad que exige la vida en común con los demás, la vida democrática. «Podría incluso mantenerse que los dispositivos institucionales que favorecen la educación de las preferencias políticas es el único problema que las dos tradiciones democráticas mantienen en común. ¿Cómo puede transformarse la "materia prima" de la voluntad popular, con toda su ceguera, egoísmo y miopía, en una serie de productos razonables y no susceptibles de ser deplorados con posterioridad?» ${ }^{15}$. Se trata, por tanto, de lograr que los individuos actúen consciente y responsablemente y, para ello, ambas tradiciones nos siguen planteando un dilema fundamental: «El dilema es el siguiente: ¿deberían las instituciones o constituciones democráticas construirse en torno a la voluntad "empírica" del pueblo o más bien en torno a su voluntad "razonable"? ¿Debieran las reglas y procedimientos constitucionales ser considerados primeramente como un mecanismo de controles, equilibrios, dispositivos autovinculantes o autopaternalistas que imponen sin distinción restricciones sobre las elites gobernantes y los ciudadanos, o debieran ser más bien vistas como mecanismos de capacitación diseñados para alterar y "desnaturalizar" la voluntad empírica del pueblo, aproximándola así a una cierta noción de voluntad razonable?... ¿Es el pueblo empírico como multitud de individuos el que constituye la base y el punto de referencia de una política democrática o lo es el pueblo que debe alcanzarse en última instancia como cuerpo colectivo con una historia y un destino comunes? ¿Es el principio de legalidad el que proporciona la legitimidad a un régimen democrático o debe más bien la legalidad someterse a algún tipo de prueba de legitimidad sustantiva? ${ }^{16}$.

Offe y Preuss siguen describiendo cómo las soluciones prácticas a este dilema, arbitradas por las modernas democracias liberales no se han ajustado a ninguna de las dos tradiciones, sino que han sido más bien fórmulas híbridas que, en vez de resolver el problema de cómo educar la voluntad empírica del pueblo, lo han puesto entre paréntesis. Analizando dos de los rasgos institucionales claves de las democracias contemporáneas: el sufragio y el estado de bienestar, concluyen que lejos de servir a la creación de ciudadanos adultos y responsables, profundizando y ampliando la democracia, han creado

15 Ibid., p. 58.

16 Ibid., p. 59. 
sociedades alienantes al sofocar las capacidades racionales y cívicas de los individuos. Tanto el sistema representativo como el estado de bienestar han pretendido conseguir el bien común, sin preocuparse de crear, primero, ciudadanos y ciudadanas capaces de trascender sus intereses particulares y egoístas. La alineación política, que se ha manifestado, al menos, en tres dimensiones: temporal (tensión entre elecciones y decisiones), social (separación entre pueblo y políticos) y sustantiva (distancia entre la ciudadanía y su mundo de la vida, y los políticos profesionales, que se traduce en una elite de miopes y oportunistas y en una ciudadanía descapacitada y cínica), ha provocado que ni la legislación realizada a través de los órganos representativos, ni la autoridad legal, hayan bastado para alcanzar la justicia (en áreas como las de protección medioambiental, relaciones entre sexos, comportamiento intergeneracional, Tercer Mundo), ya que «las instituciones representativas han sido a menudo más miopes y menos conscientes sobre los demás o sobre la propia realidad que buena parte de su electorado» ${ }^{17}$. Han sido los movimientos sociales y no los partidos políticos o parlamentos los que han luchado con más coherencia por el bien común en dichas áreas. En este contexto, Offe y Preuss afirman que se equivocan los críticos de la democracia liberal cuando creen que «el remedio evidente para los resultados irrazonables e injustos de la acción gubernamental consiste en la extensión de la codeterminación y de la participación democrática en las categorías de la población admitida a participar (mujeres, adolescentes, inmigrantes, etc.) tanto como en lo referente a las áreas sustantivas de participación (gobierno local, empresas, servicios, universidades, etc.). De hecho, esta consideración ha perdido buena parte de su capacidad de convicción ${ }^{18}$.

Se trata, por tanto, de afrontar con claridad lo que esta constatación supone y, como siguen haciendo nuestros autores, tomar buena nota de tres dificultades que de ella se derivan. En primer lugar, la idea de extender la participación a «todos» se torna inviable, cuando, «como lo demuestran las reivindicaciones de índole regionalista y sexual, el espi-

17 Para abundar en las lacras de las instituciones representativas y de la autoridad legal, véase el magnífico artículo de E. GARZÓN VALDÉs. «Instituciones suicidas», en el que analiza pormenorizadamente el comportamiento parasitario de la democracia representativa, del Parlamento, de los partidos, etc. «La ética, dirá, es indispensable para el control de las instituciones que, libradas a sí mismas, tienden a autodestruirse, si no formalmente, sí substancialmente. Lo grave no es el simple hecho del "suicidio" sino las consecuencias del mismo dado el tipo de instituciones a las que quiero referirme: la democracia y el mercado». Isegoría, N. ${ }^{\circ}$ 9, 1994, p. 64.

18 OfFe y Preuss, op. cit., p. 67. 
noso problema de definir el universo adecuado de acción e identidad no puede resolverse mediante la ampliación de la participación». En segundo lugar, cuando al tratarse de derechos humanos y civiles no se trata tanto de «lograr mayorías», cuanto de proteger determinados derechos, incluso de las mismas mayorías. En tercer lugar, existe «la decepcionante posibilidad de que la calidad de los resultados no siempre se torne superior con la ampliación del derecho de participación y codeterminación», ya que algunas acciones colectivas suelen ser más irracionales que las individuales. Los poderes de co-determinación y participación se pueden fácilmente emplear para propósitos particularistas y egoístas.

Pero, para nuestros autores, aceptar estas dificultades no tiene que llevar, como ocurre en muchos autores, a un retorno a formas predemocráticas, elitistas, autoritarias o paternalistas. La forma de hacer más razonable la democracia no está en reducir la participación, sino, precisamente, en lo contrario: «radicalizar el principio de participación democrática: generalizar las categorías de personas con derecho a la participación; generalizar las áreas sustantivas y los sectores institucionales a los que se aplique el derecho de participación, someter a sufragio las diversas preferencias existentes entre los ciudadanos/votantes a fin de organizar un conflicto social ordenado, no sólo entre mayorías y minorías (o entre trabajadores y empresarios en el caso de la "democracia económica"), sino, también, en igual medida, un “conflicto interno" entre lo que los propios individuos consideren sus deseos más y menos deseables. Semejante radicalización del principio democrático tendría como objetivo una estimulante reflexión» ${ }^{19}$. Aquí es donde las instituciones y los procedimientos cobran una importancia clave para moralizar la voluntad egoísta de la ciudadanía educándola en un proceso de deliberación.

El papel de las instituciones es, en cualquier caso, imprescindible. $\mathrm{Su}$ rol de «rigideces requeridas» para la vida en común, como dice el mismo Offe, ya que reducen la incertidumbre al proporcionar guías de acción que estructuran las prácticas políticas, debe ser asumido y valorado, sin caer en veleidades anarquizantes. En nuestros días, aunque parezca paradójico, no es ocioso el reflexionar sobre la necesidad de las instituciones coactivas y, en concreto, sobre la legitimidad del uso de la fuerza en el Estado de derecho. La deslegitimación de las instituciones democráticas en nombre de concepciones particularistas y no universalizables de la felicidad o de la identidad es hoy más que un

19 Ibid., pp. 67-68. 
riesgo. Frente a los particularismos premodernos, no hay mejor solución que la de las instituciones democráticas, ya que éstas expresan la aventura emancipadora del «desarraigo». Creo que hay que abundar en esta definición de la democracia como «lugar común del desarraigo», en el sentido más genuino del «altruismo universal». El caso del nacionalismo vasco me ha llevado a reflexionar sobre este tema, que trae consigo la necesidad de clarificar algo tan relevante para la vida política como es el comprender la relación entre legalidad, legitimidad y legitimación.

Pero ¿qué ocurre con la vinculación entre instituciones y recursos morales? ¿Cuál es su relación? Sabemos que la regla del derecho corre el riesgo de ser inoperante, si no conlleva la convicción de sus destinatarios. Para lograrlo, debe engendrar, en un nivel mucho más «micro», la acción de los ciudadanos conscientes. Pero ¿qué es actuar de manera consciente y responsable? Offe nos dice que consiste en llegar a adoptar, frente a los propios actos la perspectiva del experto, del otro generalizado y de uno mismo proyectado en el futuro, lo que no es fácil en un mundo en el que los fenómenos de causalidad son complejos e inciertos. Una institución nos parece pertinente, cuando refuerza la reflexividad: tanto más importante en sociedades como las nuestras en las que las presiones centrífugas representan un grave problema.

Reflexividad significa incitar a los actores a razonar sobre sus preferencias hasta ser críticos en relación a sus propias elecciones, a abrirse al aprendizaje para poder evaluar mejor las consecuencias de sus actos, a autolimitarse desarrollando la identificación con el otro. La reflexividad es el paso de las racionalidades locales y sectoriales a formas de racionalidad más englobantes, del autocentrismo a la empatía, de la miopía a las visiones de más largo alcance. La reflexividad es, pues, una racionalidad más amplia en la decisión política, reduciendo el riesgo de tener que lamentarse una vez tomada por falta de alguno de los siguientes criterios cualitativos de una voluntad «racional»e «ilustrada»: "Semejante voluntad tendría que ser a la vez "consciente de los hechos" (por oposición a la ignorancia y al doctrinarismo), consciente del futuro (por oposición a la miopía) y consciente del otro (por oposición al egoísmo)» ${ }^{20}$. El trabajo de reflexividad se sitúa en el nivel simbólico de la construcción social de las situaciones a través de su definición; de este ejercicio de definición se esperan resultados positivos para el bienestar colectivo. El autor pone el ejemplo de medidas que se

${ }^{20}$ Ibid., p. 58. 
toman en materia ecológica. Algunas empresas pueden oponerse al principio, pero, con una «future regarding», podrán descubrir que son medidas para el bien de todas las personas.

Para promover las decisiones esclarecidas y los recursos morales de los actores, las instituciones deben favorecer la comunicación entre ellos, para remediar la fragmentación, permitiendo corregir los errores, gracias a la puesta en práctica de procedimientos iterativos, en los que los mecanismos de retroacción tienen un papel importante. La dimensión dialógica debe ser fuerte en el funcionamiento institucional: deliberación de alguna forma consigo mismo para observar, experimentar y razonar sobre sus elecciones, confrontación con los otros puntos de vista y tentativa de ajuste mutuo, aprendizaje sobre la base de la opinión de expertos que disponen del saber especializado apropiado.

\subsection{Profundizar y extender la democracia hoy}

La mirada retrospectiva que acabamos de echar nos plantea el reto de saber argumentar a favor de una radicalización de la participación democrática y el saber hacerla plausible a través de instituciones y procedimientos que desarrollen, en los individuos y grupos, la capacidad de deliberar reflexivamente y de comportarse con criterios razonablemente democráticos. Pero, si dicho reto ha sido históricamente difícil, creo que se ha complicado aún más en nuestros días, dadas las nuevas y crecientes amenazas que la complejidad del contexto actual plantea a la democracia. Citábamos, al comienzo opiniones, como la de Dahrendorf, pesimistas respecto al futuro de la democracia, porque, una década después de la revolución de 1989, parece tener pertinencia preguntarse, con grave preocupación, por dicho futuro. El regreso de los fundamentalismos, especialmente los derivados de las políticas de identidad, fruto a su vez del multiculturalismo y de los particularismos excluyentes, incapaces de convertirlo en interculturalismo, el proceso de globalización económica y sus efectos radicalmente desigualitarios, las tendencias autoritarias y populistas, y la ausencia de una autoridad mundial, que favorecen el creciente protagonismo de organizaciones y fuerzas transnacionales de dudosa legitimidad democrática, son la evidencia empírica que ha de ser tenida en cuenta para poder repensar adecuadamente la cuestión de la democracia. ${ }^{21}$

21 Véase D. Held. La democracia y el orden global. Del Estado moderno al gobierno cosmopolita. Piados, Barcelona. 1997, pp. 169 ss. 
Pero, con ser muy graves estas amenazas, a alguna de las cuales, me referiré más adelante, creo imprescindible reflexionar sobre una clave estructural que dificulta algunos procedimientos para lograr la profundización y extensión de la democracia, como es la enorme y siempre creciente complejidad de nuestras sociedades.

La complejidad en nuestras sociedades se manifiesta en la presencia de intereses plurales y de demandas heterogéneas en la sociedad. El riesgo de una sociedad compleja es que puede llegar a estallar a causa de los particularismos y de la fragmentación: sectores profesionales, comunidades culturales, subconjuntos territoriales, individualismos y particularismos de todo tipo. Además, los problemas que hay que resolver son también complejos: tienen diversas causas y sus parámetros evolucionan de forma imprevisible en el tiempo. La complejidad es sinónimo de contingencia: ningún valor social se impone, sin contestación, sobre los otros, y ninguna elección aparece como evidente, ya que no se está seguro de sus consecuencias. Los poderes públicos se enfrentan a esta dificultad: ¿cómo asegurarse el apoyo a sus decisiones en un mundo fragmentado y cómo asegurar la rectitud de sus elecciones, ya que suelen ignorar el alcance y las salidas de los problemas que tienen que asumir?

La complejidad social tiene, pues, importantes consecuencias tanto sobre la forma de participar los ciudadanos como en la forma de gobernar los políticos. Los poderes públicos se ven obligados a optar, haciendo de la necesidad virtud, por acciones y reformas modestas, prudentes, fragmentarias, tanto más cuanto son vulnerables a la vigilancia creciente de que son objeto por públicos tan diversos como atentos ${ }^{22}$. Los ciudadanos se ven avocados con frecuencia una confusión de roles que son difíciles de integrar en una actividad autónoma y responsable.

No me voy a detener a describir la abundante literatura sociológica que ha estudiado el fenómeno de la complejidad social ${ }^{23}$. Baste con citar

22 J. Leca expresa así la dificultad que tienen hoy los gobiernos en la toma de decisiones: «En una situación de autonomía de los policy fields, "decidir" que la balanza comercial será excedentaria, el número de crímenes reducido o el paro ilegal, tendrá tanto sentido como hacer decidir por referéndum que la muerte es inconstitucional, porque es contraria a la DUDH» (LECA, «Ce que l'analyse de politiques publiques pourrait apprendre sur le gouvernement démocratique», en Révue française de science politique, N. ${ }^{\circ} 46,1$. 1996, p. 126); véase del mismo autor: «La démocratie à l'épreuve des pluralismes», Ibid., N. ${ }^{\circ} 46,2$, pp. 225-279.

${ }^{23}$ Remito al lector interesado a la obra de Y. PAPAdOPOUlos, La Démocratie directe, en el apartado titulado «Complejidad y acción pública», pp 237 ss. Es conocida la obra ya clásica de D. BELL, Las contradicciones culturales del capitalismo. Alianza Editorial. Madrid. 1974, en la que Bell analiza las contradicciones entre los diferentes ámbitos de la realidad... 
corrientes de análisis como la representada por Niklas Luhmann: una sociología funcionalista de la diferenciación y centrada explícitamente en la complejidad, como característica clave de la modernidad ${ }^{24}$. Luhmann, después de subrayar el alcance de la fragmentación de nuestras sociedades en subsistemas autónomos, con sus lógicas diferentes, con criterios crecientemente auto-referenciales, hasta llegar a la «clausura operacional», generando importantes disfunciones sociales, rechaza la primacía de la esfera política sobre las demás esferas y confirma la primacía de la esfera económica que, con su poder de chantaje y de seducción, va colonizando a toda la sociedad. El resultado es que, al no existir ya una jerarquía incontestada de valores entre los códigos de las esferas sociales, la complejidad equivale a contingencia e incertidumbre. Así, las sociedades complejas están constantemente sometidas a las presiones centrífugas y padecen de una aguda falta de cohesión, de normas comunes suficientemente poderosas, ya que la cohesión no puede imponerse desde arriba, como ocurría, en otras sociedades, con la religión o la verdad del partido. Pero, tanto porque se da una contestación al proceso de colonización economicista por parte de otras esferas, como la cultural, la ecológica, la de la identidad, como porque no es tolerable una ausencia total de regulación, el sistema político debe intervenir para regular los problemas entre los diversos sectores sociales, ya que su legitimidad depende de su capacidad para imponer coactivamente los objetivos comunes que mantengan a la sociedad cohesionada. El pesimismo de Luhmann respecto a la acción reguladora del gobierno es claro, ya que los problemas politizados son aquéllos que los diferentes sectores sociales no son capaces de resolver por su cuenta y el sistema político, que no dispone de recursos superiores a los de otros sectores sociales, debe afrontar retos enormes, a la vez que su acción es permanentemente contestada.

Hay otras corrientes más empíricas, también funcionalistas, que han analizado la complejidad, sin teorizar tanto como Luhmann, ni caer en su pesimismo, ya que, para ellas, la complejidad social ha hecho necesarias nuevas formas de acción, como son los procesos de negociación y de cooperación entre los diferentes sectores sociales y nuevas formas de participación de los públicos. El proceso de fragmentación horizontal de la sociedad en sectores, por razones de especialización funcional (que habría sustituido la división de clases), respondería a una lógica evolucionista (volveríamos a un proceso de refeudalización).

${ }^{24}$ N. Luhmann. The Differentiation of Society, New York, Clumbia University Press, 1982. 
Finalmente, otras corrientes subrayan más el aspecto de lucha entre los diversos sectores que fieles, a la vez que presos de su propia lógica, acrecientan la cohesión ad intra y se blindan ante las demandas y exigencias de los otros sectores. Es verdad que también se pueden dar relaciones de mutuo reconocimiento y de buena vecindad entre los sectores, hasta llegar a reconocerse una división de roles y a realizar «transacciones colusivas» (acuerdos tácitos de no ingerencia, etc.) ${ }^{25}$.

Sin embargo, hay otros dos factores, sobre los que estas teorías de la complejidad no dicen nada y que, como afirma Papadopoulos, son hoy decisivos en el proceso centrífugo de nuestras sociedades. El primero es el carácter cada vez más multicultural de las sociedades: segmentación no ya sobre la base de diferencias funcionales, sino sobre la base de diferencias que para los actores reflejan identidades, es decir, «bienes primeros» según dice Rawls, en conflicto. Sabemos el potencial disgregador de los conflictos culturales y cómo son un caldo de cultivo favorable a los fundamentalismos. A pesar de que las identidades sectoriales parecen más débiles que las identidades vividas como vinculadas a la filiación, al sexo, a la lengua, a la religión o, incluso, a la clase social de origen o de pertenencia, ni las teorías sociológicas de la complejidad, ni la corriente de las políticas públicas han hecho de estas un objeto de su investigación central.

El multiculturalismo afecta también ahora a las sociedades tradicionalmente homogéneas, sobre todo, como consecuencia de la inmigración. A los conflictos de intereses les sustituyen los conflictos de reconocimiento. Aunque ninguna identidad es dada, a los ojos de los individuos, algunos elementos identitarios parecen más esenciales que otros en el doble sentido del término: importantes y «naturales»o, al menos, heredados por lazos de sangre más que escogidos o adquiridos del exterior. Las reivindicaciones de excepción frente a la homogeneización cultural son comparativamente mayores que frente al referente del mercado. En el seno de los sectores culturales diferentes, se da una presión social mayor que en los otros sectores (identidades «calientes» o «espesas», siempre afectivas, frente a identidades «frías» o «delgadas», de talante instrumental).

El segundo elemento ocultado por las teorías funcionalistas de la complejidad concierne al hecho de que la acción pública implica cada vez más la cooperación de numerosos niveles de gobierno (ciudades y

25 Papadopoulos se refiere a la obra de M. Dobry, Sociologie des crises opolitiques, Presses de la Fondation nationale des sciences politiques, Paris, 1986, en la que analiza crisis como la de la primera República italiana. 
aglomeraciones, diversas entidades regionales, Estado central, organizaciones internacionales...), lo que los ingleses llaman «multilevel-governance». También, en la cuestión territorial, el policentrismo se hace presente. Aunque haya unas relaciones formalmente jerárquicas en el proceso de tomas de decisión, los diferentes niveles son interdependientes y tejen entre ellos relaciones de cooperación conflictivas. Se trata de la cooperación entre diferentes autoridades públicas, que pueden ostentar generalmente una legitimidad electiva directa. Obviamente, los problemas de gobierno-multinivel se agravan cuando entra por medio la componente multicultural.

Además de los dos elementos señalados, hay que tener presente que el nivel de análisis escogido: sectores y subsistemas, es demasiado extenso y abstracto, como ocurría con el concepto marxista de clase social. Nadie los ha visto jamás. Es verdad que el movimiento de diferenciación funcional va acompañado del desarrollo de organizaciones especializadas que materializan, de alguna forma, a los distintos sectores de la sociedad: empresas (economía), partidos (política), universidades e institutos de investigación (ciencia), hospitales (salud), tribunales (derecho), etc. Pero las cosas no son tan sencillas, ya que ni es fácil saber a qué esfera pertenecen las grandes asociaciones de interés, ni que éstas sean representativas del punto de vista del sector en su conjunto. La complejidad no sólo concierne a las relaciones entre sectores, sino igualmente a las relaciones en su seno. Sobre todo en el sistema político, la proliferación de actores que intervienen en la toma de decisión, así como la multiplicación de instancias que pretenden tener una palabra que decir, plantean problemas de coordinación y costos de transacción y de legitimación considerables. Por eso, los arreglos neocorporatistas son esfuerzos de organización y de homogeneización (negocian unos grupos en nombre de todos, con monopolio de representación y con una estructura jerárquica). El ejemplo de Italia es claro para ver todo lo dicho hasta ahora (subsistemas, territorios, órdenes institucionales...), ya que una aproximación en clave de sectorización no sirve para aprehender la complejidad de la situación.

No hay que sobrevalorar ni la homogeneidad de los sectores, ni la cohesión de las lógicas sectoriales, ya que esto incide en el desinterés por los actores concretos, individuales y colectivos. La programación de los actores en cada esfera no puede ser absoluta, lo que exige relativizar la clausura de estas esferas, especialmente cuando los actores se encuentran en la frontera entre varios sectores, cuyos valores interiorizan. Los actores desarrollan así identidades latentes, imprevisibles. La complejidad intra-sectorial -y no sólo la complejidad inter-sectorial- debería ser tomada en cuenta como fuente de fragmentación 
(heterogeneidad de los componentes de un sector) y diversidad de sus relaciones.

Finalmente, lo que caracteriza la complejidad, no es únicamente el peso de la sectoriedad en la acción social, sino también las pertenencias múltiples de los actores. No es cierto que los sectores produzcan hombres unidimensionales, pero, contrariamente a lo que se pensaba sobre el pluralismo, el «yo múltiple» no conduce necesariamente a la apertura de espíritu, a la identificación con la otra persona y a la empatía recíproca, sino más bien al desarrollo y a la confusión de roles ${ }^{26}$.

\subsection{Aprendiendo de una discusión}

Una respuesta institucional a la complejidad parece que debería ser la complejificación del mismo sistema político: más expertos, instancias, sistemas, lugares y niveles de decisión. Cuanto mayores sean la representatividad y la apertura a la participación, dicen los participacionistas, más y mejor deben convertirse en imperativos de gobernabilidad. Pero las cosas no son tan sencillas. Una organización no puede hacerse infinitamente compleja, si no quiere caer en la sobrecarga, la parálisis y el caos. Sólo puede integrar una dosis de complejidad reducida, si quiere evitar el riesgo del centrifuguismo y de la falta de cohesión. Es una de las paradojas de la gestión de la complejidad: la integración de una organización en su entorno corre el riesgo de hacerse en detrimento de su propia integración interna (problemática clásica en sociología la de la difícil conciliación entre integración social y sistémica). La regulación de la complejidad exige poner en práctica mecanismos de comunicación y de coordinación de intereses para evitar la fragmentación. Profundizar y extender la democracia en medio de tanta

26 J. SubIRATS, en un artículo titulado «Otra política, otros partidos», dice así: «La vida se nos ha individualizado más que nunca... Probablemente cualquier nuevo intento de crear un renovado sentido de cohesión social deberá partir, como afirma Beck, del reconocimiento de que el individualismo, la diversidad y el escepticismo forman parte de nuestro actual patrimonio cultural. Constantemente nos enfrentamos a situaciones sociales ante las que ya no reaccionamos de manera unitaria. No somos sólo burgueses o trabajadores, catalanes o españoles, blancos o de color, padres, madres, hijos o hijas. Somos peatones, hermanos, productores, madres, pacientes, estudiantes, conductores, hijos, votantes, europeos y seres humanos. Saltamos constantemente de una identidad a otra. Tratando a veces de ser coherentes con un hipotético sentido estratégico. Mientras en otras sólo a posteriori pensamos que quizás nuestra reacción como padres o madres no sería la lógica si hubiéramos actuado como hijos, o que como contribuyentes deberíamos quizás cambiar nuestra opinión de votantes». El País. 8/VI/2000. De especial interés, en este tema, es el libro de MAALOUF, Identidades asesinas... 
complejidad exige saber crear mecanismos institucionales y, a la vez, ciudadanas y ciudadanos capaces de comportarse como sujetos responsables ... A la hora de responder a este reto, las oposiciones se van a dividir entre quienes creen que la única forma de gestionar la complejidad es crear elites e instituciones capaces de gestionar con eficiencia y racionalidad la complejidad, ya que desconfían de la masa de la ciudadanía ordinaria, a la que consideran incompetente y peligrosa para la gobernabilidad de la sociedad (son los elitistas) y quienes creen que la mejor forma de gestionar la complejidad y, a la vez, de desarrollar las capacidades que tienen todos y cada uno de los ciudadanos y ciudadanas es extender la democracia, en número de actores, en amplitud de ámbitos participativos y en la intensidad de la participación. Son los participacionistas que también desconfían, pero ellos lo hacen de los dirigentes y elites de todo tipo, que son sospechosos de colusión, porque persiguen sus propios intereses y porque son un peligro para la democracia. Al contrario que los elitistas, no ven ningún riesgo de ingobernabilidad en la participación.

La controversia entre elitistas y participacionistas nos debe llevar a evitar simplificaciones de escuela y a no caer ni en el pesimismo elitista, ni en el utopismo participacionista. Debemos abordar las cuestiones básicas que ambas escuelas debaten, para saber tenerlas en cuenta a la hora de profundizar y extender la democracia. Ya decíamos, al comienzo, que nuestra apuesta va a estar determinada por el cómo podremos llevarla a cabo, teniendo en cuenta qué instituciones y procedimientos son los menos inadecuados y más eficientes, y cómo lograremos que la ciudadanía sea lo más razonable en su comportamiento democrático.

Sin olvidar que los comportamientos individuales dependen en gran medida y cuanto mayor es la complejidad social, más, de los contextos institucionales en los que deben afrontar los problemas y decidir sobre su solución, es obvio que los individuos y grupos tienen sus preferencias y disponibilidades respecto a cuánto y cómo participar en los asuntos públicos. Esta es una cuestión que ha sido siempre debatida, pero, especialmente, desde que nuestras sociedades se han configurado conforme al paradigma del individualismo posesivo. El mismo Rousseau, defensor como sabemos de la democracia directa, en las Cartas desde la montaña que dirigió a los ginebrinos les decía: «No sois ni Romanos ni Espartanos, ni siquiera sois atenienses. Dejad estos grandes nombres que no os van. Sois mercaderes, burgueses, siempre ocupados en los intereses privados, de vuestro trabajo, de vuestro mercado, de vuestra ganancia; gentes para quienes la misma libertad no es sino un medio para adquirir sin obstáculo y para poseer con seguridad». Autores, 
como M. Weber, Schumpeter o, más recientemente P. Hirst y K Graham $^{27}$, han subrayado que no se debe sobreestimar el deseo de participación de la ciudadanía en general, ya que el individualismo moderno sería connaturalmente proclive a la no participación e, incluso, a la inacción colectiva. Quizás, también, sirva el mismo argumento para el individualismo «posmoderno»: el de la era narcisista de Lash, el individualismo hedonista de Lipovstky o el «presentista» de Lyotard ${ }^{28}$. En cualquier caso, la búsqueda de la «buena vida» se traduce en una actitud de complicidad con el sistema político vigente con tal de que garantice el acceso al consumo y la seguridad. Parece que estamos ante una reedición del epicureísmo, necesitado del poder que asegure el jardín tapiado, aunque, ahora, dentro del jardín, apenas si encontramos otra cosa que individuos ajenos a la reciedumbre moral de quien se esfuerza por jerarquizar éticamente sus placeres.

Seguimos, pues, ante el reto fundamental de que hemos venido hablando. ¿Cómo lograr que los individuos trasciendan sus pasiones e intereses egoístas y se comporten con la moralidad que exige la vida en común con los demás y la condición de la ciudadanía democrática?

D. Held recuerda que tenemos poca información sobre cómo funcionan las instituciones participativas, ya que las democracias representativas apenas han desarrollado esta dimensión y los teóricos de la democracia participativa han dicho muy poco sobre cómo organizar la economía y cómo relacionarla con el sistema político; cómo combinar

27 P. HiRst, que no se opone a una creciente participación ciudadana, pero vía asociaciones, argumenta a favor del sistema representativo porque requiere poco esfuerzo y conocimiento por parte del elector, a la vez que le concede poderes reales. Es la mejor forma de tener en cuenta la disponibilidad de los individuos que en nuestras sociedades complejas tienen que responder a otras numerosas demandas. Su «democracia asociativa» supone una desestatalización que debe traducirse en un aumento de las competencias devueltas a las asociaciones voluntarias democráticamente controladas, y no a empresas jerárquicamente organizadas y en busca del interés. Véase Representative Democracy and its Limits. Cambridge. Polity Press. 1990. K. GRAHAM subraya esta idea: «The volume of decisions which modern governments have to make, their complex and often technical nature, mean that the average person - of whom there are millions - simply does not have time, the knowledge or the interest to make any significant contribution to those decisions». The battle of Democracy. London, Harvester Wheats 1986, p. 128).

28 A. Touraine, refiriéndose a la creciente disociación entre gestión de la cosa pública y demanda de las personas consumidoras, dice al respecto: Los electores, que han sido ciudadanos después que trabajadores, se transforman en simples consumidores, preocupados por sus necesidades inmediatas, y, sobre todo, ansiosos de participar, al máximo posible, en la vida de la main stream, de la vasta clase media que reemplaza a la burguesía y a la clase obrera. Entre el Estado estratega y los electores consumidores, el espacio de la ciudadanía se ha vaciado y sólo ha sido ocupado por las empresas de comunicación política, por la producción y a veces la venta de votos. El País. 18/VI/1992. 
las instituciones de la democracia representativa con las de la democracia directa; cómo controlar el ámbito y el poder de las organizaciones administrativas; cómo podrían negarse a participar en el sistema político quienes lo desearan ${ }^{29}$.

\section{La democracia directa a debate}

La democracia directa ha sido vista convencionalmente por el pensamiento progresista como el supuesto remedio a las lacras y deficiencias de la democracia representativa. Los males de la democracia tendrían su remedio en más democracia. «Devolver el gobierno al pueblo», «que decidan los votantes», han sido eslóganes progresistas que han expresado la desconfianza ante todo poder u organización intermediaria, por verlos como sospechosos de defender intereses particularistas y de velar, en primer lugar, por su propia reproducción. Además, la democracia directa sería una escuela en la que las ciudadanas y ciudadanos aprenderían a valorase a sí mismos, a tener un sentimiento de utilidad por su competente contribución al bien común, a generar una relación más estrecha con los demás, a identificarse mejor con las decisiones tomadas por ellos mismos, siendo una fuente importante de legitimación del sistema político, y a controlar todo ejercicio delegado del poder, previniendo peligros de corrupción y elitismo y de marginación permanente de las personas más desfavorecidas.

Pero la democracia directa ha tenido también, desde siempre, detractores que han visto en ella un peligro para la democracia, por considerarla, más bien, demagogia y verla como fuente de numerosos y graves problemas, relacionados con la gobernabilidad y dirección de nuestras sociedades y con su incapacidad para resolver problemas complejos. Como lo formula Bobbio, «La democracia es buena para generar demandas, pero mala para satisfacerlas». Tanto la sociología política funcionalista norteamericana como el neoconservadurismo se han referido a las instituciones de la democracia directa (especialmente el referendum) como una «sobrecarga» para las autoridades políticas, que genera problemas de gobernabilidad, de estabilidad, de incertidumbre y de irracionalidad. La democracia participativa sería el resultado de la entrada en el juego político de gentes calificadas de plebeyas, desconfiadas, reivindicativas y sensibles a los discursos políticos y antisistema. Una política responsable no debería plegarse a sus presiones, en

29 D. Held. Modelos de Democracia. Alianza Universidad. Madrid. 1992, pp. 406 ss. 
nombre, precisamente, de una ética de la responsabilidad. Además, en la medida en que estas instituciones (en concreto el veto referendario como bloqueo) pueden vetar las decisiones de las autoridades políticas, se convierten en fuentes de inmovilismo y parálisis institucional, siendo capaces de anular en un solo día el paciente trabajo parlamentario de años e impidiendo la modificación del statu quo.

Se trata, pues, de saber valorar los pros y los contras que las instituciones de la democracia directa pueden tener en cada caso concreto y decidir sobre su pertinencia para lograr el objetivo de profundizar y extender la democracia. Es la perspectiva dialéctica la que mejor puede dar razón de la realidad democrática. Por un lado, la democracia directa perturba el trabajo de las elites (sobrecarga y bloqueo), por el otro, puede ser fuente de aprendizaje y de reorientaciones por una y otra parte. A su vez, los dirigentes no carecen de recursos para influir sobre los portavoces de las demandas referendarias, esperando que se integrarán, gracias a sus pruebas de apertura. La ambivalencia y la plurivocidad de la democracia directa son evidentes por lo que respecta a la gobernabilidad de las sociedades.

Me voy a limitar aquí a señalar algunas de las «promesas no cumplidas de la democracia directa», por utilizar la fórmula de Bobbio. Lo haré, siguiendo al ya citado Papadopoulos. Fundamentalmente, me referiré a su capacidad de generar recursos morales y de posibilitar una verdadera ciudadanía, argumento central de sus defensores.

Si la democracia directa es «un sistema político de puertas abiertas», que deja penetrar «bocanadas de aire fresco» que sanean y dinamizan al sistema político, incitando en los gobernantes el sentido de la responsabilidad, es fundamentalmente porque simboliza a la perfección la proximidad entre ciudadanía y gobernantes, entre el cuerpo electoral y elegidos. El sentimiento de que se comparten convicciones, ethos, intereses y preferencias es la mejor fuente de legitimación de un sistema político. Al contrario, la crisis de su legitimación está en indicadores como son la pérdida de confianza en los gobernantes y de identificación con los partidos, la emergencia de movimientos populistas cuyo discurso antielitista refleja el resentimiento por la traición y la corrupción de los dirigentes, la abstención que se sabe golpea, sobre todo, a las personas más desfavorecidas, la propagación de visiones cínicas y negativas de la política, etc. Además, por las puertas abiertas de la democracia directa, pueden entrar reivindicaciones y propuestas más plurales y menos condicionadas que las que permite filtrar la rigidez del sistema político, incluso introduciendo la discusión sobre temas tabú (como la supresión del ejército), y puede generarse la creación de una mejor opinión pública. 
Pero, por las puertas abiertas también pueden entrar «corrientes de aire» que pueden hacer enfermar al sistema. No nos referimos, ahora, a las críticas ya mencionadas de los elitistas, sino a las promesas que no se han cumplido y a las desilusiones que la democracia directa ha generado en la gente más consciente y más progresista, al no lograr lo anteriormente señalado.

Parece ser que los Movimientos Sociales son poco amigos de los referéndum, porque les suponen numerosos costos de diverso tipo, como su des-radicalización (para lograr el apoyo masivo se suavizan las demandas, creando así un comportamiento convencional y conformista... El ejemplo del feminismo es claro, ya que, en Suiza (sufragio en 1971), ha sido tardío y menos radical que en otros lugares (caso de USA: sufragio en 1920); la burocratización y la centralización de las organizaciones, generando un componente elitista en su seno; la monetarización de la democracia directa y de las consecuentes desigualdades (la necesidad de dinero para las campañas influye no sólo en el voto, sino también en la previa recogida de firmas para exigir el referendum).

Hay otros recursos no monetarios que también son importantes y que inciden peyorativamente en la democracia directa, como son los organizativos y los retóricos. La complejidad y dificultad de las cuestiones sometidas al voto popular y la reducción de la opción política al sistema binario del «síı o «no» hacen que la democracia directa sea particularmente propicia a la demagogia.

Junto a los factores precedentes, hay uno que, paradójicamente, pervierte las virtualidades positivas de la democracia más que ningún otro y la convierte en un sistema legitimador de la desigualdad y de la exclusión de las personas más desfavorecidas. Nos referimos al comportamiento utilitarista e insolidario de los votantes que se acentúa en la democracia directa, ya que no existen en ella los controles y mediatizaciones contextuales de la democracia representativa. Al margen de las deliberaciones de la campaña, no hay ningún otro medio coactivo que le obligue al individuo a tener en cuenta el punto de vista del otro y a comportarse solidariamente, teniendo en cuenta el bien común, si no está personalmente inclinado a hacerlo. En la democracia directa, no hay límites institucionales al individualismo ni sanciones al comportamiento estrictamente egoísta. Por eso, dice Papadopoulos, la democracia directa puede resultar contraproducente respecto a un ideal de justicia social en nuestras sociedades desigualitarias (cuestiones fiscales). Las minorías corren peligro ante unas mayorías que pueden convertirse en tiránicas, si no tienen contrapoderes que las limiten (la práctica del «free riding», las reacciones emotivas ante la pena de muerte, ante el 
aborto, etc). Sabemos que la democracia directa no permite ponderar las decisiones en función de la intensidad de las preferencias de unos y otros.

Aunque es posible minimizar dichos riesgos, al recordar que las medidas iniciadas por la vía de la petición popular rara vez alcanzan la mayoría de votos, sin embargo, iniciativas que buscan restringir los derechos de las minorías — raciales, étnicas, lingüísticas, homosexuales, portadores de sida, etc. - a no ser discriminadas en el empleo, vivienda, educación o disfrute de las infraestructuras públicas, suelen tener éxito. En USA, más de tres cuartas partes de las 74 iniciativas acerca de estas cuestiones presentadas entre 1959 y 1993, han sido aprobadas. No es, pues, prudente ahorrarse dispositivos institucionales que limiten, vinculen u obliguen a los decisores, especialmente, cuando se trata de los derechos fundamentales que hay que garantizar, al margen de las mayorías que los apoyen o no. El control judicial es especialmente útil.

Autores, como Weber o Schumpeter, han resaltado los efectos desigualitarios derivados de la democratización de las formas de administración, ya que no suelen ser las personas más necesitadas o desfavorecidas quienes se comprometen y participan, sino todo lo contrario, quienes disponen de tiempo, recursos y experiencia para una actividad que tiene demasiados costos para quienes no están integrados.

El mismo Offe explica la oposición neoconservadora a las políticas del EBK, como tránsito de una percepción en términos de bienes públicos a otra percepción más desconfiada en términos de costos y beneficios individuales. El homo oeconomicus utilitarista se convierte en paradigma del individuo contemporáneo. La ausencia de solidaridad y la ubicuidad del déficit de civismo son rasgos subrayados por Offe: «The masses may be premodern in their basic beliefs and understandings and therefor incapable of empathizing with those outside their own tribe, clan, or cult or of accepting them as citizens with equal rights. Or thy may be postmodern - so alienated and differentiated, so self-absorbed, and so cynical about political action that they lose all sense of competence or enjoyment in their role as citizens. Whether they have not yet acquired their cultural capital or have already begun to deplete it, modern democracies cannot depend just on habituation and civic education. They must continuously renew their shared norms and understandings through deliberation, compromise, loyalty, trust, community action, and respect for human and civic rights» ${ }^{30}$.

30 Offe, C y P.C. Schmitter (1995). «The Future of Democracy», en S.M. LiPSET (ed.), The Encyclopredia of Democracy. Londres. Routledge, vol. 2, p. 513. 
En la democracia directa, la ciudadanía ordinaria no tiene ninguna obligación de ser «políticamente correcta». Presentarla como un paso suplementario hacia la democratización corre el riesgo, si se carece de un clima de solidaridad, de reforzar las exclusiones de los grupos necesitados de un esfuerzo del resto de la sociedad para mejorar su posición.

Ante esta situación, las burocracias estatales se sienten obligadas a sortear los canales democráticos para mejorar la situación de las poblaciones marginalizadas, que están socialmente estigmatizadas para importantes franjas de la opinión pública. Esto plantea un problema de legitimidades en concurrencia. Según los estándares democráticos clásicos, el recurso al circuito parlamentario y, mejor aún, al de la democracia directa confiere legitimidad, pero puede poner en peligro las relaciones de cooperación fundadas en la confianza mutua entre los actores de la red. Las legitimaciones experto-local y democrática-global no son fácilmente compatibles, ni acumulables. No se debe descartar la hipótesis de que la mejora de las condiciones de vida de las personas más débiles sólo la garantiza una coalición cerrada de tecnócratas y de profesionales.

Si lo aquí descrito es cierto, se nos plantea una cuestión fundamental, que ya se planteaba en tiempos del despotismo ilustrado: «ise puede imponer la Ilustración»?; Rousseau lo formulaba con su «se le obligará a ser libre» ${ }^{31}$. La vieja idea madisoniana de la necesaria mejora de la voluntad popular no es tan absurda - dejando de lado simplificaciones elitistas - porque plantea la cuestión de las condiciones de mejora de esta voluntad, sobre las que el «direct-majoritarianism» permanece mudo $^{32}$.

Así, pues, podemos concluir que la contribución de la democracia directa a la producción de recursos morales es bastante débil: ausencia de incitaciones a la cooperación y a la reflexividad, ausencia de condiciones de deliberación satisfactoria, mercantilización, efectos ambiguos sobre los movimientos sociales, comportamientos utilitaristas, selectividad y

31 HeRmET, G. «Dictature bourgeoise et modernisation conservatrice: problèmes méthodologiques de l'analyse des situations autoritaires», en Révue Française de sicience politique, 25: 6, décembre 1975, pp. 1029-1061.

32 Según FishKIN, se da la creencia de que todo lo que refleje «direct-majoritarianism» - combinación de la regla mayoritaria con la democracia directa- es bueno: Anything that causes the system to conform better to our shared perception of majority opinion, and anything that supplants effective decision making by the peoples themselves, comes to be perceived as more democratic. Democracy and Deliberation. Newe Haven-Londres, Yale University Press. 1991, p. 24. También el libro de Guy HeRMET Le peuple contre la démocratie, da una lista impresionante de ejemplos desmintiendo la ficción de las virtudes populares. Fayard. Paris. 1989. 
delegación de hecho para quienes tienen interés en preservar unas rentas de situación y se oponen a la redistribución de recursos, externalización de los costos sobre los sectores más débilmente organizados y carentes de voz. Se trata de cuestionar el hecho de la participación en el sentido meramente cuantitativo.

\section{3. ¿La democracia electrónica o el sondeo deliberativo, como solución?}

Si las instituciones de la democracia directa (referendum) han mostrado sus carencias democráticas, tanto en lo que a la participación efectiva se refiere como, sobre todo, por lo que se refiere a una participación nacida de una conciencia ilustrada, parece que la democracia electrónica podría subsanar dichas carencias. Ni el tamaño, ni la información serían ya problema insoluble para las nuevas tecnologías (televisión, internet), puestas al servicio de la extensión y profundización democráticas. En efecto, tanto la creciente democratización de su uso, como la enorme cantidad de información con la que podrá contar la ciudadanía, abren una puerta a la esperanza y a la utopía de futuras «comunidades virtuales» capacitadas para desarrollar sus potencialidades interactivas, así como para deliberar y tomar juntos decisiones orientadas al bien común.

Pero la teledemocracia plantea también no pocos ni pequeños problemas, especialmente los relacionados con la calidad de la información de la ciudadanía que va a participar gracias a estas nuevas tecnologías. Supuesta la democratización del acceso a dichas tecnologías, la enorme cantidad de información sobre la que no hay control se convierte en un grave problema para ciudadanos y ciudadanas normales sin capacidad para poder «surfear» con competencia cognitiva y política. Además de su uso para fines demagógicos y plebiscitarios (campaña de Perot en USA), este medio puede servir para reproducir las exclusiones. En efecto, a la irresponsabilidad y mala fe del emisor se puede añadir la del receptor, que se puede dejar llevar por el egoísmo y la ceguera, ya que está solo ante una pantalla, no debe dar cuentas a nadie y nada le empuja a la empatía y a la solidaridad con los demás. Se ha subrayado, también, en este sentido, el peligro de banalización del voto, que pierde así su sentido ritual. No parece que sea el mejor medio para generar recursos morales.

Numerosos autores ha alertado ante los riesgos de la teledemocracia. Fishkin ha afirmado que la teledemocracia está tan impregnada de «direct-majoritarianism» como la democracia referendaria clásica: dé- 
ficit deliberativo, manipulación demagógica y riesgo de atentar contra los derechos de las minorías ${ }^{33}$.

Una forma más específica de obviar los problemas de la tele-democracia es la que propone R. Dahl en su obra La democracia y sus críticos. Es el llamado «sondeo deliberativo». Se trata de que un minipopulus (unas mil personas), conectado a la red, tenga la oportunidad de deliberar sobre un tema durante más de un año. La experiencia, sobre la que Fishkin ha seguido reflexionando, permitiría reconciliar la democracia - toma de decisión por el pueblo- con el ejercicio consciente del poder. El sondeo deliberativo se diferencia del sondeo clásico en que, mientras este último se supone que nos dice lo que el público piensa (aunque sabemos que suele estar poco informado e inducido a responder de una forma concreta por el mismo cuestionario), el primero describe lo que el público en su conjunto pensaría si de antemano tuviera la ocasión de informarse y de reflexionar sobre las cuestiones que se le plantean. El sondeo deliberativo debe reunir condiciones óptimas para la representatividad (grupo elegido por sorteo), para la deliberación y la reflexividad (discusiones intensivas entre participantes que, para poder estar mejor informados, cuentan con el apoyo de expertos), hasta posibilitar el cambio de posiciones entre quienes participan.

Pero, a pesar de las condiciones utópicas que hacen pensar en lo valioso del instrumento (aunque hay experiencias en Estados Unidos y Gran Bretaña), también existen problemas e interrogantes que cuestionan su fiabilidad como garantía de más y mejor democratización de la sociedad. En primer lugar, está el problema del sorteo como método democrático. No todos están de acuerdo con que sea el método mejor y más democrático ${ }^{34}$. En segundo lugar, es un sondeo meramente consultivo y seguramente demasiado caro, para que su aceptabilidad y practicabilidad sean asumidas como el camino normal de democratización, sobre todo, cuando los cambios de posición inducidos por la deliberación no han sido espectaculares, en los lugares en donde se ha puesto en práctica.

\section{4. ¿Qué hacer?}

Si la forma de profundizar y de extender la democracia no pasa necesariamente por las formas que aparentemente son más democráticas, como son las instituciones de la democracia directa, ¿no es una

33 FishKin. Op. cit., pp. 21 ss.

${ }^{34}$ Véase B. Manin. Los principios del gobierno representativo. Alianza Editorial. Madrid. 1998. 
incoherencia seguir manteniendo preocupaciones «participacionistas»? Si la cuestión de cuáles son las formas democráticas apropiadas y cuál el grado de democratización óptimo de los procesos es cada vez más discutida, dada la creciente complejidad de nuestras sociedades (ya, tampoco está tan claro el tema de la democracia económica ${ }^{35}$ o el del papel de los expertos y su independencia respecto a la toma de decisiones en las instituciones socioculturales, que deben cumplir unos objetivos concretos de carácter solidario), ¿con qué criterios debemos reformar o crear nuevas instituciones y profundizar en la democracia?

Si el problema fundamental al que nos siguen enfrentando las evidencias empíricas es la escasez de recursos morales que padecen nuestras sociedades democráticas, precisamente cuando amenazas y retos, de una envergadura hasta ahora desconocida, nos plantean de forma perentoria su necesidad para poder seguir hablando razonablemente de democracia, creo que lo primero que hay que hacer es responder a este problema. La respuesta no debería seguir siendo, como hemos visto que ha sido hasta ahora, esquivar y mantener un modelo híbrido de democracia que, a la postre, se traduce en un progresivo vaciamiento de la democracia de los ciudadanos y ciudadanas, a favor de una democracia de consumidores.

Hay que comenzar por reafirmar (o recuperar) la fe democrática que tanta evidencia empírica ha podido debilitar o apagar. No se trata de limitarnos a comprobar resignadamente «las promesas incumplidas de la democracia», condenándonos a la apatía y al abstencionismo. Una democracia razonable no puede guiarse por los criterios del relativismo moral, del mero legalismo o de la «razón instrumental, que acaban negando los criterios que, al comienzo, veíamos que constituyen la naturaleza de una sociedad cabalmente democrática (ni el positivismo jurídico, ni el pragmatismo político, deben guiar la actividad humana).

35 Si bien hay una corriente de opinión, heredera de la tradición socialista, favorable a demandar democracia económica (Bobbio, Barber, Dahl, etc.), en nuestros días, la democracia económica está en progresivo deterioro. Además, ésta no aporta pruebas empíricas avalando sus virtualidades cívicas. Como señalan algunos autores, las relaciones entre diferentes esferas de participación son complejas. La experiencia muestra que los trabajadores están más interesados en cuestiones que tienen que ver con la mejora de sus condiciones laborales (salario, seguridad, salud, vacaciones, etc.) que con la cuestión del poder en la empresa. El contraejemplo de Mondragón se suele idealizar en exceso. La dependencia estructural de nuestras sociedades con respecto al capitalismo ha hecho decaer las estrategias socializadoras de la economía de otros momentos. D. Held cita, por ejemplo, los costos y dificultades de las empresas democratizadas respecto a las estructuradas jerárquicamente. Además, la democracia económica no está inmune ante derivas de carácter particularista y elitista (también, la experiencia de Mondragón es ilustrativa de esto). 
Más allá del estoicismo resignado o del cinismo satisfecho, debemos creer que los seres humanos podemos seguir siendo los sujetos políticos que decidimos con autonomía cómo queremos construir nuestras sociedades.

Aunque no tengamos la capacidad de ser filósofos reyes, al menos, debemos saber dar razón de que en nuestro comportamiento social y político nos mueven criterios de justicia, conforme al designio que el del Protágoras ponía en la mente de los dioses, una vez que el plan de éstos fue frustrado por la inexperiencia del héroe Epimeteo. «Los dioses, al llegar el momento señalado por el Destino de crear los linajes mortales, mandaron a Prometeo y Epimeteo que distribuyeran de manera conveniente entre ellos todas las cualidades que tenían que poseer. Epimeteo rogó a Prometeo le dejara a él el cuidado de hacer por sí mismo la distribución: "Cuando ésta esté lista — dijo- tú inspeccionarás mi obra". Concedido el permiso, él se puso manos a la tarea. En esta distribución, dio a los unos la fuerza, sin la rapidez; a los más débiles, les asignó la cualidad de la rapidez... Ahora bien: Epimeteo, cuya sabiduría era imperfecta, había ya gastado, sin darse cuenta de ello, todas las facultades a favor de los animales, y le quedaba aún por proveer de las suyas a la especie humana, con la que, falto de recursos, no sabía qué hacer. Estando en este embrollo, llega Prometeo para inspeccionar el trabajo. Ve todas las demás especies armoniosamente equipadas para vivir, y al hombre, en cambio, desnudo, sin calzado, sin abrigos, sin armas. Y había llegado el día señalado por el Destino para que el hombre saliera de la tierra a la luz... Los hombres, una vez. reunidos, se herían mutuamente, por carecer del arte de la politica, de forma que comenzaban de nuevo a dispersarse a morir. Entonces Zeus, preocupado al ver que nuestra especie amenazaba con desaparecer, mandó a Hermes que trajera a los hombres el pudor y la justicia, para que en las ciudades hubiera armonía y lazos creadores de amistad.». La distribución, sigue diciendo el texto, se debía hacer entre todos por igual. "Entre todos — dijo Zeus-, que cada uno tenga parte en estas virtudes; ya que si solamente las tuvieran algunos, las ciudades no podrían subsistir, pues aquí no ocurre como en las demás artes; además, establecerás en mi nombre esta ley, a saber: que todo hombre incapaz. de tener parte en la justicia y el pudor debe ser condenado a muerte, como una plaga de la ciudad» ${ }^{36}$. Es sabido que Hermes era el chapucero de los dioses. La política, tal como estamos condenados a practicarla los humanos, es una chapuza que nunca llegará a satisfacer las exigencias

36 Platón. El Protágoras. Obras Completas. Aguilar. Madrid. 1966, pp. 166 ss. 
de «lo divino» que llevamos dentro. Personalmente, suscribo la definición que de ella daba Alain «es la búsqueda de soluciones probables a problemas insolubles».

Se trata de recuperar la base moral de la democracia. Frente al relativismo moral, debemos saber afirmar, con coherencia y firmeza, el núcleo de la tradición democrática occidental: la centralidad de los «derechos humanos», convirtiéndolos en el «coto vedado» ${ }^{37}$, en el núcleo duro de cualquier consenso normativo construido con las garantías razonables de lo que D. Held llama «el experimento mental democrático $^{38}$. Luchar por la defensa de los derechos humanos de todos y cada uno de los seres humanos, desde la «afirmación de un derecho público democrático» que, en nuestros días, debe adquirir la forma de un «derecho democrático cosmopolita», como plantea Held. Frente a la apatía y al abstencionismo, hay que mejorar los mecanismos de representación en los partidos políticos y de las asociaciones, a la vez que se fomenta la actitud participativa en todos aquellos ámbitos de la realidad en que se juegan los intereses de la justicia bien entendidos. Hay que educar en la obediencia responsable a las leyes legítimas, es decir, una obediencia que debe ser compatible con la objeción de conciencia y con la desobediencia civil. Frente al peligro de la oligarquización y burocratización excesivas del poder y sus derivas particularistas (lupeterie), hay que regenerar la sociedad civil y poner en juego la capacidad de ejercer la autonomía democrática de individuos y grupos humanos de todo tipo.

\section{Afirmar la autonomía democrática}

D. Held, después de haber analizado con lucidez las grandes transformaciones de nuestro mundo, que le llevarán a formular su proyecto de «democracia cosmopolita», afronta el reto de repensar la construcción de la democracia desde sus fundamentos. La piedra angular de esta reconstrucción es el que ha sido, hasta nuestros días, el criterio

37 Véase cómo formula la idea de coto vedado E. Garzón Valdés, refiriéndose al mercado, en el artículo ya citado. «Se trata de la exclusión de bienes no susceptibles de ser sometidos a las reglas de la oferta y de la demanda... Lo negociable y acordable no puede ser decido en el mercado mismo sino que requiere la aceptación de un sistema normativo superior. Este es de la justicia como virtud social. Sólo desde él pueden formularse los arreglos institucionales que confieren calidad moral al instrumento del mercado. Quien pretenda invertir el razonamiento e inferir valores morales de la actividad incontrolada del mercado habrá de perder su cabeza bajo la guillotina de Hume». P. 121.

${ }^{38} \mathrm{La}$ democracia, dice HeLD, es incompatible con formas de desigualdad y de exclusión graves. Véase La democracia y el orden global, pp. 198 ss; pp. 268 ss. 
central de toda verdadera construcción democrática: la afirmación del principio de la autonomía ${ }^{39}$. Consciente de que la abstracción del principio puede convertirlo en inocuo y carente de virtualidad política, especialmente en un mundo que se está «globalizando» de espaldas a la lógica democrática, Held distinguirá entre la autonomía ideal (no significa inmediatamente realizable), la autonomía alcanzable (posible y razonable) y la autonomía urgente (perentoria ante daños graves y evitables). Consciente de que la autonomía ideal, que identifica con la aplicación integral de los cinco criterios ya citados de R. Dahl, no siempre es posible, distinguirá entre aquellas formas de ejercer el poder y de limitar la autonomía que son legítimas y las que son ilegítimas. Asimismo, distinguirá entre un ejercicio individualista de la autonomía y una afirmación de la autonomía como un principio estructural, que él denomina «autonomía democrática».

Para D. Held, son incompatibles con la democracia, porque imposibilitan la autonomía de personas y grupos, aquellas formas de ejercer el poder que «generan asimetrías sistemáticas de perspectivas de vida y limitan y erosionan las posibilidades de participación política». Esta es la definición de lo que él llama nautonomía ${ }^{40}$. Consciente de que la consolidación del principio de autonomía, que debe llegar a traducirse en la vida de cada uno, ha sido diferente según contextos históricos e ideologías, Held contempla «siete esferas de poder» o planos, en que la nautonomía puede darse y «es menester examinarlos todos: la seguridad personal, el bienestar físico y psicológico, las oportunidades de ser miembro activo de la preservación de la identidad cultural, las posibilidades de unirse a las asociaciones cívicas, la capacidad de ejercer influencia sobre la agenda económica, las posibilidades de participar en los debates políticos y en las actividades electorales, y las posibilidades

39 La definición kantiana de la misma sigue siendo la referencia válida en nuestros días. «Una constitución que promueva la mayor libertad humana posible, según leyes que garantizan que la libertad de cada uno puede coexistir con la libertad de todos los demás, es, desde todo punto de vista, una idea necesaria que debe ser la base no sólo del primer proyecto de una constitución política sino también de todas las leyes posteriores. Requiere que nos abstraigamos de los impedimentos existentes, que quizá se deban menos a la naturaleza humana que al descuido de las ideas genuinas en el proceso de legislación... Incluso si (el "Estado perfecto") nunca se materializara, la idea que hace de esta máxima un arquetipo... sigue siendo correcta. Pues nadie puede o debe decidir cuál es la instancia suprema que en la humanidad ha de detener su progreso y, por lo tanto, cuán amplia es la distancia que todavía existe entre la idea y su ejecución. Pues esto dependerá de la libertad, que puede trascender todo límite que queramos imponer». Escritos políticos de Kant. Citado por HELD. Op. cit. p. 265.

40 D. HeL. Ibid., p. 210. 
de actuar sin ser amenazado por el uso de la violencia o la fuerza física» ${ }^{41}$. Proteger estas esferas de la vida es el objetivo prioritario del derecho público democrático, que no sólo debe garantizar constitucional y legalmente el ejercicio de la capacidad de los individuos en cada una de dichas esferas, sino que debe establecer la agenda de la política democrática para materializar con éxito dicho objetivo. Obviamente, se deja la puerta abierta a la interpretación exacta de cómo hay que aplicar la agenda en cada caso concreto.

La distinción entre niveles «alcanzables» y niveles «urgentes» de autonomía es importante, ya que sirve para poder distinguir hasta dónde y cómo es exigible el principio de igualdad democrática en la aplicación de todos y cada uno de los derechos políticos, sociales y económicos. Siendo conscientes de que la nautonomía nunca va a ser totalmente erradicada, lo importante es saber cuáles son sus legítimas limitaciones, cuáles son las prioridades que hay que definir, etc. En cualquier caso, hay un criterio que Held formula así: «El compromiso con la autonomía democrática implica un compromiso con la satisfacción de las necesidades de los que están en desventaja en materia de autonomía y, simultáneamente, con la reducción de las prerrogativas de los poderosos que impidan el desarrollo de un orden plenamente democrático. Si bien no crea un procedimiento de decisión que resuelva los choques de prioridades políticas, este compromiso sí define una orientación y un punto de partida inequívocos. Fuera de esto, será un asunto de los ciudadanos y sus representantes decidir, por medio del diálogo, la deliberación y el debate, de qué manera exactamente se van a distribuir en definitiva los bienes y servicios. Este elemento de indeterminación política es tan inevitable como deseable» ${ }^{42}$.

A la luz de este concepto de autonomía democrática que garantiza el desarrollo de todas y cada una de las personas (niveles de autonomía urgente y alcanzable) que componen la sociedad, hay que plantearse la cuestión decisiva de la forma y la naturaleza adecuadas de la comunidad política. Hasta ahora, la forma de comunidad política que mejor ha garantizado el ejercicio de los derechos y de las obligaciones ha sido el Estado-nación democrático. La forma concreta en que se han plasmado el reconocimiento y el ejercicio de los derechos humanos ha sido el de

41 Las «esferas de poder» correlativas son: cuerpo, bienestar, cultura, asociaciones cívicas, economía, violencia organizada y relaciones coercitivas, e instituciones regulatorias y legales. Véase, Ibid., pp. 215-216. Véase la tabla de las pp. 236-237, en la que el autor describe un mapa de esferas de poder y de los tipos de derechos y dominios de acción habilitados por los derechos que corresponden a cada una de dichas esferas.

42 Ibid., pp. 261-262. 
derechos de ciudadanía. Hoy, cuando el marco del Estado-nación ha sido desbordado y cuestionado por diferentes procesos, de diverso signo (globalización-particularismos), se nos plantean serios interrogantes sobre dicho marco, en primer lugar, y, también, sobre la pertinencia del concepto de ciudadanía para dar todavía cabida a la afirmación de la autonomía democrática.

En primer lugar, debe quedar claro que los derechos que componen lo que antes hemos llamado núcleo duro de la autonomía democrática no pueden hipotecarse a ninguna concepción reduccionista de la ciudadanía o de la universalidad. En segundo lugar, parece obvio que la autonomía sólo la podrá garantizar adecuadamente una comunidad política que no se vea sometida o amenazada por el poder de otras comunidades políticas o por las actividades de sujetos transnacionales que atraviesasn sus fronteras. Se impone, pues, la convicción de que, para afirmar la autonomía democrática $\mathrm{y}$, con ella, los derechos humanos de forma históricamente suficiente, se necesita una estructura legal internacional, que D. Held denomina «derecho democrático cosmopolita» y que tiene una característica fundamental: debe tener vigencia dentro y fuera de cualquier frontera.

No me voy a extender aquí en describir la naturaleza y la institucionalización de esta democracia cosmopolita. Remito a la obra de D. Hed que venimos comentando ${ }^{43}$. Sin embargo, sí que creo necesario recoger de dicha obra la afirmación de que la forma de hacer plausible la categoría de ciudadanía es convertirla en «ciudadanía múltiple». La complejidad del universo político debe llevarnos a la construcción de un nuevo orden político, con nuevas formas y niveles de gobierno, en el que las asociaciones, ciudades y naciones sean tan democráticas como las regiones, los continentes y las redes globales. Las personas podrían disfrutar de la ciudadanía de todas aquellas comunidades políticas, unas más inmediatas y otras más universales, que influyen sobre sus vidas y condicionan el ejercicio de sus derechos. Más adelante, me referiré a esta cuestión.

Ahora, en vez de seguir ideando cómo debería ser este nuevo orden internacional, prefiero centrar mi atención en unas realidades que, en mi opinión, son, hoy, la amenaza que pone en peligro cualquier posibilidad de profundizar en la autonomía democrática. Me refiero a las que considero tres fuentes de nautonomía más importantes, como son el capitalismo, tal como lo defiende la ideología neoliberal; las llamadas

43 Véase el capítulo 12 de la obra, titulado La democracia cosmopolita y el nuevo orden internacional. 
«políticas de identidad», que, en parte, provocadas por el universalismo imperialista y homogeneizador del capitalismo, afirman un pluralismo etnocultural en clave particularista y excluyente; y, finalmente, el control y manipulación de la cultura y de la opinión pública, por los grandes centros de poder, que instrumentalizan los Medios de Comunicación y las redes de información para distribuir asimétricamente el conocimiento, impidiendo el desarrollo de las capacidades cognitivas de la ciudadanía.

\subsection{Neoliberalismo (capitalismo neoliberal) y negación de la autonomía democrática}

El modelo de «democracia legal» que defiende el neoliberalismo, de la mano de autores como Nozick o Hayek ${ }^{44}$, se presenta como la mejor forma de comunidad política, ya que permite que los individuos puedan desarrollar todas sus capacidades, con la dosis mínima de intrusión por parte del Estado y con la garantía de un marco tan verdaderamente libertario como es el del mercado. El imperio de la ley, entendido como marco legal general, tanto nacional como internacional, es suficiente garantía para el ejercicio de los derechos y libertades. Pretender subvertir el orden del mercado y de la federación de Estados ultraliberales es iniciar un «camino de servidumbre». Su concepción de una individualidad, sustentada y clausurada en el ejercicio de un derecho de propiedad privada incuestionable, a quien hay que hacer justicia, respetando su libertad, es alérgica al concepto de «justicia social», que considera expresión de una ideología colectivista y totalitaria y representa el argumento de la perversidad del Estado distribuidor, ya que logra justamente lo opuesto a lo que proclama ${ }^{45}$. Pero, sabemos que es

${ }^{44}$ La obra más divulgada de Nozick ha sido Anarquía, Estado y Utopía. FCE. México. 1988; De HAYEK: Camino de servidumbre, Universidad Autónoma de Centroamérica. San José. 1986; Los fundamentos de la libertad, Unión Editorial. Madrid. 1990; Derecho, Legislación y libertad (3 vol.), especialmente, el tomo 3, «El orden político de una sociedad libre». Unión Editorial. Madrid. 1976.

45 La incoherencia de este discurso neoliberal queda reflejada en estas palabras de Garzón Valdés: «Pero, el fenómeno de la perversidad se manifiesta justamente en una de las versiones más radicales de la filosofía política contemporánea, como es la de R. Nozick. Esto arroja serias dudas acerca de la viabilidad del proyecto libertario: si lo que se pretende es asegurar la libertad individual, la guía de la mano invisible a partir de un supuesto estado de naturaleza lockeano nos conduce a un Estado que, sólo si prescinde del consenso fáctico de sus ciudadanos, es decir, viola el principio de un individualismo radical, puede asegurar la paz social. Esta es una consecuencia realmente trágica para un neoliberal». Ibid., p. 105. 
imposible, para la inmensa mayoría de individuos, dejados a sus propios medios en la llamada economía de libre mercado y con un Estado mínimo, el que puedan afirmar sus derechos más elementales. La propiedad privada y el capitalismo sólo son favorables para quienes gozan del privilegio de ser propietarios o capitalistas. Solamente un control razonable del mercado por el poder político y una redistribución de los recursos orientados con criterios de justicia social pueden generar las condiciones para que todos los individuos se desarrollen con autonomía en todas las esferas de su vida.

Estamos, como dice P. Bourdieu, ante un «capitalismo sin disfraz, ni restricción, un capitalismo que ha sido racionalizado, ajustado al límite de su eficacia económica gracias a la introducción de formas modernas de dominación ("gestión") y de técnicas manipulativas tales como la investigación de mercado, el marketing y la publicidad comercial» ${ }^{46}$.

Creo no simplificar en exceso, si digo que este modelo «utópico» de democracia, que desconoce las verdaderas fuerzas que controlan y determinan las leyes del mercado y que son ajenas a la voluntad libre de los individuos, es una de las principales formas de legitimación de la desigualdad y de la exclusión social generadas por la lógica economicista que rige las relaciones económicas. La supeditación de la política a la economía y los enormes condicionamientos a los que los poderes económicos someten a los Estado y demás poderes legítimos impiden que éstos puedan garantizar los derechos humanos a su ciudadanía (en el caso en que dichos Estados sean democráticos y así lo pretendan), son muestras evidentes de que el capitalismo neoliberal es fuente permanente de nautonomía y de que es incompatible con la democracia. En mi opinión, la negación más radical y masiva de los derechos humanos y de la autonomía democrática está en el actual proceso de globalización económica y en la ideología que lo legitima, incluso, en su expresión más salvaje e inhumana ${ }^{47}$. Los poderes que controlan los grandes flujos económicos no sólo no están supeditados a ninguna comunidad política concreta, sino que son, de hecho, impunes de flagrantes delitos en contra de los derechos humanos de todas las generaciones, imposibilitando no sólo niveles de autonomía «alcanzables», sino, también, niveles de autonomía «urgentes».

46 P. Bourdieu. «Una utopía razonada; contra el fatalismo económico», en New Left Review. N. ${ }^{\circ}$ 0. Enero 2000.

47 Véase E. Dussel. Etica de la liberación, en la edad de la globalización y de la exclusión. Trotta. Madrid. 1998. 
Aún siendo consciente de que no hay que simplificar la crítica al capitalismo, ya que hay diversas formas de capitalismo ${ }^{48}$, y de que, mientras no haya alternativas razonables, tendremos que priorizar la transformación de la forma de capitalismo menos nautonómica, creo que es pertinente, como lo hace el P. Calvez, «reabrir la cuestión del capitalismo». En el texto titulado «los silencios de la Doctrina SociaI de la Iglesia», dedica el capítulo $\mathrm{V}$ a este tema clave y dice que, en la Doctrina Social de la Iglesia, se ha tratado de algunas variedades de propiedad y de capitalismo que se han considerado ilegítimas. Pero no se ha abordado la cuestión de la propiedad y del capitalismo en sí mismos, entendiendo por capitalismo algo tan específico como lo siguiente: «hay capitalismo allí donde el capital, o bien los medios de producción, están en manos de pocas personas, mientras que la inmensa mayoría de los seres humanos no pueden aportar al proceso de producción más que su trabajo. Esta situación, incluso sin estar acompañada de una ideología "economicista" o materialista, de reducción del trabajo al estatuto de mercancía, o de liberalismo extremo, arrastra, como veremos, en sí misma, un gran peligro de injusticia y de división social. ¿No habrá que trabajar, por tanto, para superarla? Es la cuestión que es indispensable plantear... Incluso, después de cien años de fracaso en la búsqueda de soluciones, parece que debe ser tomada muy en serio de cara al futuro ${ }^{49}$.

Las declaraciones de la Iglesia sobre la propiedad han evolucionado mucho a lo largo del tiempo, como ya hemos visto. Pero no se ha explicitado todavía el rechazo del capitalismo. En efecto, se ha discutido muy a menudo del capitalismo e, incluso, se ha llegado a condenarlo en algunos circunstancias, pero siempre contemplándolo desde algún ángulo específico y calificándolo con algún adjetivo como «primitivo»,

48 Seguramente, la fórmula más viable de superación de esta fuente de anautonomía es el potenciar las formas de capitalismo más proclives a posibilitar niveles de autonomía urgentes.

49 J-I. Calvez. Les silences de la Doctrine Sociale Catholique. Les Editions Ouvrières. Paris. 1999. p. 70. Cita Calvez algunos textos en los que se habla de propiedades ilegítimas, que tienen detrás la toma de posición decisiva de Pío XII en 1941: «Todo hombre, en cuanto ser vivo dotado de razón, tiene por naturaleza el derecho fundamental de usar de los bienes materiales de la tierra... Tal derecho individual jamás debería ser anulado por otros derechos ciertos y reconocidos sobre los bienes naturales. El orden natural que viene de Dios requiere tanto la propiedad privada y la libertad de comercio recíproco de los bienes en cambios y donaciones, como también la función reguladora del poder público sobre ambas instituciones. Sin embargo, todo ello queda subordinado al fin natural de los bienes y no debería hacerse independientemente del derecho primero y fundamental que concede su uso a todos...». 
«salvaje», desde una perspectiva ideológica y cosmovisional ${ }^{50}$. Sin embargo, no se hace referencia a la situación intrínseca del capitalismo, considerado en sí mismo, sino que siempre se lo califica de exageradamente liberal y mercantilista. Así, en la Centesimus Annus, se refiere Juan Pablo II a un capitalismo «aceptable», «un sistema económico que reconoce el papel fundamental y positivo de la empresa, del mercado, de la propiedad privada y de la responsabilidad que ésta implica en cuanto a los medios de producción y a la libre creatividad en la economía» (n. ${ }^{\circ} 42$ ). Nada se dice de una forma de distribución concreta de la propiedad de los medios de producción. Uno puede preguntarse si se trata del capitalismo en el sentido preciso de la palabra.

En el fondo, pues, la Iglesia nunca ha hablado directamente de la desigualdad típicamente capitalista $\mathrm{y}$, si ha atribuido males al capitalismo, ha sido a un capitalismo afectado de una interpretación, de un «error de pensamiento», de una ideología economicista o materialista, incluso liberal. Para Juan Pablo II, parecería que la situación capitalista no plantea problemas si las personas actúan con responsabilidad y en un marco jurídico conforme con la ética. Pero no se explicita ni cuestiona la situación en sí misma. Leyendo a Juan Pablo II, parece como si el capitalismo no fuera un problema, con tal de que los seres humanos actúen con responsabilidad y en el marco del derecho conforme a la ética.

¿De dónde nace la dificultad? «El capitalismo es, solamente, el hecho de que la propiedad del capital está en pocas manos, mientras que la mayoría de la gente no puede llevar a la producción económica más que su trabajo. Esto se muestra problemático, ya que el capital es naturalmente poderoso, atrae hacia él el ahorro que le permite crecer y acumular. Por el contrario, el trabajo es más débil, aunque se asocien diversos trabajadores y, al final, aquél debe realizarse en las condiciones que le imponen los que controlan el capital. Estos últimos, aunque pocos, deciden constantemente en el cambio social.»

Sigue precisando más y afirma que el capital se presenta fácilmente en gran cantidad, nada limita la masa de capital que puede poseer una persona. El detentor de capital pone éste a disposición de la producción, pero no está obligado nunca a hacerlo en un plazo limitado. Puede esperar la ocasión más favorable sin caer, por tanto, en la penuria, menos aún en la miseria. Su persona no depende o sólo relativamente

50 Véase, por ejemplo, la denuncia del primer capitalismo salvaje y del economicismo o materialismo práctico, en la Laborem exercens, n. $^{\circ} 11$ y 13; del capitalismo exageradamente liberal, n. ${ }^{\circ} 36$, etc. 
para su subsistencia inmediata o próxima» ${ }^{51}$. Con el trabajo, explica a continuación, ocurre todo lo contrario. Es muy personal, es precario, apenas puede imponer sus condiciones (aunque la asociación pueda suavizar algo la situación; pero, incluso ésta, es más fuerte entre los capitalistas; además, la situación de los parados y de otros excluidos no cuenta con la asociación), difícilmente acumula recursos como el capital.

Calvez se pregunta por la etiología de tal situación y contesta que no existe una respuesta general, ya que la desigualdades naturales pueden bastar para que, en un momento, se puedan traducir en desigualdad de detención de capital (gracias a un progreso científico y técnico significante) y producir todos los efectos antes señalados. Además, el capital ha sido diferente, según las épocas (tierras, medios de producción). Pero rechaza que esta desigualdad del capitalismo sea una fatalidad de la existencia humana o del mundo moderno. De hecho, como recuerda, en la historia se ha limitado esta desigualdad, mediante los bienes comunales. El ser humano sólo resiste a su egoísmo, cuando la ganancia posible está limitada y hay una ventaja en ser solidario, pero no lo hará cuando la ganancia sea ilimitada, ya que el apetito se hace irresistible (más que colmado).

Frente a quienes argumentan que la desigualdad genera progreso y que la presión sobre el trabajador impide que éste trabaje poco, Calvez reconoce que la desigualdad capitalista es fuente de progreso material y que la necesidad es, en cierta medida, un estímulo (aunque no siempre, como lo muestran los campos de trabajo), pero se cuestiona el derecho de unos individuos a imponer la necesidad y el estímulo sobre otros: ¿el azar, la suerte de una acumulación material antecedente, en la que no se ha tenido ningún mérito (herencia)? Frente a quienes argumentan que los intentos por hacer salir a los seres humanos de esta desigualdad (siglo XIX y XX) han provocado más males que los que se derivan de la desigualdad capitalista,

51 También Calvez dice que merece la pena recordar el punto de vista de Pablo VI sobre el libre intercambio que, en el contexto real de las relaciones capitalistas del actual orden internacional, lleva a pensar de otra manera. Es preciso, por tanto, que la Iglesia reabra la cuestión del capitalismo, porque el capitalismo en sí mismo es un problema para la Doctrina Social de la Iglesia. Por eso, en un apartado, que Calvez titula «el Problema», añade: «La Iglesia debería reflexionar sobre lo que parece que es un problema social constante, al menos, una amenaza constante, no en razón de la libertad, sino porque se mantiene la situación de desigualdad designada corrientemente como capitalismo — porque éste ya no es el mero hecho del empleo de capital, ni el mero hecho de la existencia del derecho de propiedad (a no ser que se suponga que el derecho de propiedad en general conduce automáticamente a la situación capitalista). Y hay que hacer frente al problema (no sólo al del liberalismo ilimitado)». Ibid. 
como lo ha dicho el mismo Juan Pablo II al criticar al estatismo colectivista $^{52}$, hay que afirmar que, aunque el Papa no excluye que los dirigentes socialistas podrían haber actuado de otra manera que la totalitaria, la desigualdad capitalista sigue siendo irracional e injusta.

El fracaso del colectivismo, e incluso de las nacionalizaciones, «no disculpa la desigualdad capitalista, o el capitalismo desigual», de los males sociales que fácilmente engendra. Tampoco hay que resignarse, dice Calvez, a aceptar la tesis de un capitalismo moderado, según la cual basta con paliar las consecuencias, especialmente las más pesadas, del sistema, imponiendo al capital diferentes cargas sociales directas y obligándole a compensar las desigualdades consecuentes que arrastra y a remediar la división de otra forma inevitable (tesis asumida por la Socialdemocracia). Hay una primera razón para no contentarse con esta actitud, que es la insatisfacción de paliar solamente las consecuencias, sin enfrentarse a las causas. Una segunda razón, más importante, es la autonomía humana del trabajador, que está herida al no poder tomar en sus manos toda una parte de su propio destino. Por esta razón, es difícil pararse en la búsqueda de soluciones mejores que la del capitalismo desigual ya conocido. La Iglesia debe decirlo con la mayor claridad en su Doctrina Social de la Iglesia, si no quiere acomodarse a un sistema que perturba la convivencia social.

Concluye Calvez su reflexión con un apartado titulado «la subjetividad a respetar en la socialización», en la que, reconociendo que no hay soluciones simples y que muchos ya se han resignado con la que tenemos, anima a la búsqueda, como la evoca Juan Pablo II en la Laborem Exercens, cuando dice que hay que encontrar una forma de propiedad orientada hacia el servicio al trabajo, hacia una cierta socialización del capital, creando cuerpos intermedios que permitan una «subjetividad de la sociedad» ${ }^{53}$. Calvez sugiere la propiedad cooperativa para algunas actividades que no requieren mucho capital, a la que ve mucho futuro, y apunta medidas destinadas a posibilitar una cierta igualdad de partida: reparto de capital, capitalismo popular. El problema, en estos casos, está en que el control del capital no sea tan anonimizado que sus detentores no ejerzan en nada su responsabilidad. Para ello, deberían sindicarse (ejemplo de inversores «morales», supervisores de las empresas, influyendo en la elección de las producciones y retirando sus fondos a las empresas que actúen en contra de la dignidad humana). Es un proceso en ciernes, comenta el P. Calvez.

52 Laborem Exercens, n. ${ }^{\circ} 14$.

53 Laborem Exercens, n. ${ }^{\circ}$ 14-15. 
La cuestión de la democratización de la economía y, más en concreto, de la empresa es una cuestión muy debatida. Pero, a pesar de que, como ya hemos dicho, sea hoy una causa a la baja, no faltan razones que la hacen razonable y deseable. R. Dahl, por ejemplo, sale al paso de los argumentos de quienes se oponen a ella, recordando que dichos argumentos se parecen mucho a los que utilizan quienes defienden la teoría del tutelaje ${ }^{54}$. También D. Held aboga por una democratización de la economía, que debe comenzar por afirmar el principio de la autonomía, dentro de las empresas ${ }^{55}$. Pero los objetivos que propone Held para la democratización de la economía exigen un marco de política social, adecuado al nuevo contexto, que haga viable la aplicación de las medidas democratizadoras (medidas legales: tasas, sanciones, condiciones de ayuda...; acuerdos orientados a posibilitar el nivel «urgente» de autonomía a los países en vías de desarrollo, etc.) y, como condición imprescindible, una autoridad que, legítimamente, promueva y garantice dicha política ${ }^{56}$.

Si los argumentos utilizados por el P. Calvez son sólidos, tanto cuando denuncia la naturaleza desigualitaria y deshumanizadora del capitalismo, en sí mismo considerado, como cuando afirma que se impone la búsqueda de salidas al mismo, si no queremos resignarnos y claudicar ante la injusticia y la desigualdad, creo que dichos argumentos se cargan de razón cuando pensamos en el actual proceso de «globalización» del capitalismo $^{57}$. En mi opinión, frente a las corrientes neoconservadoras y

54 Véase R. DAH. La democracia y sus críticos, pp. 396-398.

55 «Para mantener las relaciones legales democráticas, las corporaciones deberán respaldar, de jure y de ipso, el compromiso con el imperativo de la autonomía. Lo que esto implica es que las compañías deben cumplir sus objetivos estratégicos y obtener sus beneficios económicos sin quebrantar la exigencia de tratar a sus empleados y clientes como personas libres e iguales, tal como lo especifica el derecho público democrático. Es decir, que dentro de su esfera de competencia, las compañias deben promover condiciones prácticas de trabajo que preserven la salud y la seguridad, la capacitación y el bienestar, las capacidades de intervenir en el debate y la crítica (de la compañía y su personal, entre otras cuestiones) y la facultad de formar asociaciones independientes (en este caso, sindicatos y organizaciones profesionales). Pero la instalación del derecho público democrático dentro de las compañías implicaría, sobre todo, el compromiso de erradicar las fuentes económicas de anautonomía y, en consecuencia, de garantizar un "ingreso básico" y "avenidas de acceso" a la propiedad productiva y financiera». La democracia global... p. 300.

56 «El tema central es reconocer la necesidad de una nueva autoridad transnacional capaz de deliberar acerca de las prioridades y pautas globales de inversión y gasto públicos y de las situaciones de emergencia económica». Ibid., p. 308.

57 El mismo CALVEZ en un capítulo del mencionado libro sobre los silencios de la Doctrina Social católica, dedicado al capitalismo financiero actual concluye que hay un importante vacío en la doctrina social por lo que a esta cuestión se refiere. Véase op. cit., pp. 58 ss. 
neoliberales que, no sólo llaman explícitamente a una situación de estoicismo resignado ${ }^{58}$, sino que, además, sacralizan el capitalismo de forma escandalosa ${ }^{59}$, la Doctrina Social de la Iglesia debe alzar su voz profética, sin complejos, recuperando su verdadera tradición; no la tradición del jusnaturalismo lockeano, sino la de los Padres de la Iglesia que se atrevían a preguntar a los ricos por la injusticia de sus riquezas ${ }^{60}$; la tradición del Evangelio cristiano que necesita ser adecuadamente interpretado, pero no desalarse ni pervertirse.

Al menos, debería hacerlo, con la radicalidad que lo hizo P, Bourdieu, al recibir el premio Ernst Bloch, en Ludwigshaffen, en 1997, y pronunciar un discurso, que ha recogido el número 0 de la revista New Leflt Review, bajo el título «Una utopía razonada: contra el fatalismo económico», que ya he citado antes. La denuncia del neoliberalismo y de los efectos perversos que la política neoliberal está provocando en la vida de tantos millones de seres humanos, le lleva a proponer el ejercicio

58 Cito un texto ya clásico que refleja bien esta actitud. «No estoy diciendo que la sociedad capitalista sea una sociedad justa. Estoy diciendo que hay una concepción capitalista de la justicia que es viable. Si alguien les promete una sociedad justa en esta tierra es un mentiroso y un charlatán. Creo que no es este el destino de la naturaleza humana... Pero, si ustedes no aceptan esta forma de ver las cosas y realmente piensan que la vida puede ser radicalmente diferente de lo que ahora es, si creen realmente que la justicia puede prevalecer sobre la tierra, si les gusta comenzar por tomarse muy en serio expresiones como "justicia social" y pensar que la función de la política es rescatar el mundo de sus demonios: abolir la guerra, abolir la pobreza, abolir la discriminación, abolir la envidia, abolir, abolir, abolir. Les digo que no vamos a abolir nada de todo eso. Si les arrojamos por una ventana, volverán a entrar de la forma más imprevista. Las reformas de hoy despertarán los demonios de mañana. Si uno se toma con estoicismo esta circunstancia, precondición básica de la vida social, el capitalismo se hace mucho más tolerable. Pero, si no, si uno pide a la vida más de lo que ésta puede dar, entonces, el capitalismo es el sistema equivocado, porque ni promete más, ni da más. Todo lo que da es una gran abundancia de bienes materiales y una gran dosis de libertad para afrontar los problemas de la condición humana por su cuenta». I. KRISTOL. «A capitalist conception of justice» en R.T. DE George-J.A. Pichler (eds.). Ethics, Free Enterprise and Public Policy. New York. Oxford University Press. 1978. pp. 68-69.

59 Véase la obra de M. NovaK. El espíritu del capitalismo democrático. Ed. Tres Tiempos. Buenos Aires. 1983.

60 «Dime, ¿de dónde te viene a ti ser tan rico?, ¿de quién recibiste la riqueza?, y ése otro ¿de quién la recibió? Del abuelo —dirás—, a través del padre. ¿Y podrás, remontándote por el árbol genealógico, demostrar la justicia de vuestras posesiones? Seguro que no podrás. Necesariamente, en su principio y en su raíz, hay una injusticia. ¿Que cómo llego a esa conclusión? Porque, al principio, Dios no hizo rico a uno y pobre a otro, ni tomó al uno y le mostró grandes yacimientos de oro y al otro lo privó de este hallazgo. No, Dios puso delante de todos la misma tierra. ¿ Cómo, pues, siendo todo común, tú posees tierras y más tierras, y el otro ni un terrón?». JUAN CRISÓSTOMO. Homilías sobre la Primera Carta a Timoteo. Homilía 12. n. 4. 
de un «utopismo reflexivo», tal como lo concebía Bloch, a quien cita: «Un utopismo que actúa "en virtud de su pleno conocimiento anticipado y consciente de la tendencia objetiva", la posibilidad objetiva y real de su "época": un utopismo que dicho de otro modo, "anticipa psicológicamente una realidad posible". El utopismo racional se define por estar tanto contra las "meras ilusiones que invariablemente han cargado de descrédito a la utopía", como contra las "perogrulladas filisteas fundamentalmente preocupadas por los hechos"; se opone a la herejía, derrotista en último término, de un automatismo objetivista, según el cual, las contradicciones objetivas del mundo bastarían por sí mismas para revolucionar el mundo en el que se producen, así como al "activismo por el puro activismo", puro voluntarismo basado en un exceso de optimismo» ${ }^{61}$. Fiel a este utopismo, Bourdieu no se conforma con una respuesta abstracta de intelectual, sino que presenta su contribución personal a la «resistencia contra la Europa de los banqueros y contra la restauración conservadora». Tras decir que la construcción de la Europa democrática hace falta «una combinación acordada de los intelectuales, de los sindicatos y de las asociaciones más diversas, de todos los países europeos» (para él, más urgente que la composición de programas comunes, es crear instituciones comunes: parlamentos, federaciones internacionales, asociaciones de todo tipo - camioneros, editores, maestros... defensores de los árboles, los peces, los champiñones, el aire puro, la infancia y todo lo demás - en las que se puedan discutir y elaborar programas europeos comunes), señala cuatro áreas prioritarias en las que ya está trabajando (el Estado social y sus funciones; la unificación de los sindicatos; la armonización y modernización de los sistemas educativos: la articulación entre la política económica y la social), en especial, iluminando los obstáculos sociales a los que se enfrenta la auténtica europeización de dichas áreas. Cito el párrafo conclusivo de su discurso ya que nos introduce en el siguiente apartado: «sólo me resta formular la cuestión que debería estar en el centro de cualquier utopía razonada referente a Europa; ¿cómo creamos una Europa realmente europea, libre de toda dependencia respecto a los imperialismos - empezando por el imperialismo que afecta a la producción y distribución cultural en particular, por la vía de las restricciones comerciales- y también liberada de todos los residuos nacionales y nacionalistas que continúan impidiendo que Europa acumule, aumente y distribuya

61 E. Bloch. L'esprit de l'utopie, Paris, 1977, vol. I. P. 176, citado Por P. Bourdieu en New Left Review. N. ${ }^{\circ}$ 0. 1997. 
todo aquello que es más universal en la tradición de cada una de las naciones que la componen?» ${ }^{62}$.

\subsection{Pluriculturalismo y «politicas de la identidad»: Nacionalismo etnocultural versus democracia}

Ya hemos hablado de la enorme complejidad de nuestras sociedades, uno de cuyos rasgos más relevantes es su creciente carácter multicultural que, en algunos lugares concretos, se ha convertido en el problema número uno para la convivencia democrática, sobre todo, cuando soluciones inadecuadas del mismo han generado un proceso anautonómico.

Las causas que han dado origen a este fenómeno son diversas. Yo quisiera subrayar aquí, entre otras, a la lógica «irreversible» de la modernidad que, con la afirmación de sus dos rasgos más definitorios: el pluralismo y la secularización, nos impiden soñar con legitimidad en sociedades caracterizadas por su carácter «comunitario». La homogeneidad propia de las «comunidades» tradicionales ha ido desapareciendo de tal forma que hoy no se pueden encontrar sociedades modernas que no sean radicalmente pluralistas. Como dice, E. Hobsbawn, «Nunca se utilizó la palabra "comunidad" de forma tan indiscriminada y vacía como en las décadas en las que las comunidades en sentido sociológico se vuelven difíciles de encontrar en la vida real» ${ }^{63}$. Se refiere Hobsbawn a las reacciones que, sobre todo, a partir de los años sesenta, se han dado, frente a uno de los últimos episodios de este proceso de radicalización del pluralismo más erosionadores de toda homogeneidad comunitarista, como ha sido la llamada «globalización» y a las que califica de «políticas de la identidad».

En efecto, uno de los rasgos de estas últimas décadas, en las que la experiencia de los procesos de transformación y cambio sociales ha sido especialmente fuerte y en las que se ha percibido, quizá como nunca, los efectos disgregadores y anómicos de dichos procesos, «los hombres y mujeres buscan grupos a los que poder pertenecer, con seguridad y para siempre, en un mundo en el que todo lo demás resulta movedizo y cambiante, en el que ya nada es seguro. $Y$ encuentran lo que buscan en grupos de identidad» ${ }^{64}$.

62 P. Bourdieu, ibid.

63 E. HobsBawn cita su obra La edad de los extremos, recientemente traducida al castellano, en «La izquierda y la política de la identidad», New Left Review, N. ${ }^{\circ}$ O. 2000.

64 Ibid.

Véase E. TugenghadT. «Identidad Personal, Nacional y Universal», en Ideas y Valores. N. ${ }^{\circ}$ 100. 1996; Ch. TAYLOR. Las fuentes de la identidad. Debats. N. ${ }^{\circ}$ 68. 2000 
Sin entrar ahora a analizar la compleja cuestión de «la identidad» 65 , tanto en su interpretación «eriksoniana», como en la «herderiana», o la de sus complejas imbricaciones en lo que podríamos llamar la «ontología de los social», me limito a citar cuatro rasgos que, para el mismo Hobsbawn, son definitorios de la «identidad colectiva». En primer lugar, las identidades colectivas se definen negativamente; es decir, contra otros. En este sentido, las identidades colectivas no se basan en lo que sus miembros tienen en común, que a menudo es muy poco, sino en la opción de querer ser un «nosotros» frente a los «otros». Aunque sus señas de identidad identitarias no sean físicamente objetivables, hay una tendencia a pensarse como grupos «naturales» más que como grupos socialmente construidos. En segundo lugar, las identidades no se dan, en la vida real, como algo único y uniforme. Nadie tiene una única identidad, que pueda ser compartida tal cual por otras personas. Los seres humanos tenemos identidades múltiples y desde ellas y con ellas afrontamos el bricolaje de la identidad. En tercer lugar, las identidades no son fijas sino que se desplazan continuamente y se pueden cambiar, si es necesario (grupos no étnicos pueden convertirse en grupos con conciencia étnica). Finalmente, la identidad depende del contexto, un contexto que puede cambiar (la gente ignoraba lo que era ser judío antes de establecerse los criterios nazis).

Las políticas de la identidad son una de las salidas que se han venido dando al problema del pluralismo, primero, (ya en construcción del estado-nación moderno, cuando este pierde su original idea universalista, los derechos de los ciudadanos, y persigue la cohesión étnica del conjunto con políticas agresivas) ${ }^{66}$ y del pluriculturalismo, más tarde, consistente en negar la identidad múltiple e imponer una identidad exclusiva que determina la acción política y con ella la vida social de todos los ciudadanos y ciudadanas.

Una forma típica de política de la identidad, que desgraciadamente hace sentir su presencia amenazadora en nuestros días, es la del nacionalismo etnocultural. El caso del nacionalismo vasco radical es, para mí, el ejemplo más próximo de cómo se quiere construir una sociedad moderna desde la imposición de una pretendida identidad vasca, que, según los intérpretes del proyecto nacionalizador, habría perdido su cohesión y su homogeneidad de comunidad, debido a fuerzas ajenas a la lógica del propio proceso histórico. La construcción de la nación

\footnotetext{
65 Véase E. Tugenghadt. «Identidad Personal, Nacional y Universal», en Ideas y Valores. N. ${ }^{\circ}$ 100. 1996; Ch. TAYLOR. Las fuentes de la identidad. Debats. N. ${ }^{\circ} 68.2000$

66 Tugenghad, ibid.
} 
vasca se debe hacer, según esta política de la identidad, imponiendo a una sociedad radicalmente plural (¿plurinacional?) una identidad etnocultural (por definición particular) que cohesione y homogeneice a todos/as. Quien no asume como propio este imperativo de pertenencia a la identidad etnocultural es considerado enemigo y excluido de la «comunidad» nacional... Ya sabemos las consecuencias que esta política trae consigo...

Si la autonomía democrática se define por posibilitar el desarrollo de la pluralidad de identidades dentro de un clima de respeto y tolerancia, no parece que sea viable en el marco de las llamadas «políticas de identidad», que supeditan cualquier otro objetivo, aunque éste sea el del núcleo básico de la autonomía democrática, a la afirmación de una identidad particular y excluyente.

La nación, en el sentido etnocultural, se opone a la nación en el sentido cívico. Las naciones cívicas, las que no han pervertido su vocación «universalista» y moderna, tratan la identidad etnocultural de la misma forma que tratan otras identidades particulares, como la religión.

Creo, pues, que todo nacionalismo que, en nuestras sociedades seculares y plurales, pretenda construir una comunidad política, imponiendo una forma de identidad particular, como es la etnocultural, es una fuente nautonomía, ya que niega los derechos de todos aquellos ciudadanos/as, que ven cómo se les niega la posibilidad de desarrollar su identidad múltiple.

Soy consciente de que la compleja relación entre identidad personal, nacional y universal no es fácil y que hay razones que explican y legitiman ciertas reacciones identitarias frente al proceso desestructurador y desintegrador de la modernidad, en sus mútilples expresiones. Es obvio que, en buena medida, los nacionalismos etnoculturales y excluyentes son reacciones modernas ante las carencias y fracasos del liberalismo «universalista». Pero no siempre ni necesariamente es así. A mí me parece que no hay que dejar de lado la pertinencia de las interpretaciones del nacionalismo desde la clave del poder y de la instrumentalización que éste hace de todo lo que es útil para permanecer en él, entre otras cosas, de la dimensión etnocultural. Asimismo, el nacionalismo subraya, a veces, la dimensión etnoculural para no tener que afrontar directamente la cuestión de la igualdad y de la ciudadanía social. Creo que es importante tener esto presente a la hora de pensar en soluciones al problema de la «construcción nacional» ${ }^{67}$. En cualquier

67 Véase Breully. Nacionalismo y Estado. Pomares-Corredor. Barcelona. 1990. 
caso, pienso que no hay otra fórmula para resolver los problemas que la que apuesta por la autonomía democrática y la aplica coherentemente ${ }^{68}$. El problema de la instrumentalización nacionalista de todo lo que no suponga una asunción legitimadora de su proyecto esencialista y dogmático de nación, incluidas las instituciones democráticas, es, en mi opinión, una de las dimensiones antidemocráticas más relevantes del nacionalismo. El caso vasco es, de nuevo, paradigmático de lo que de$\operatorname{cimos}^{69}$.

La comunidad política democrática es un bien en sí mismo que no puede ser instrumentalizado ni por el individuo, como sucede con el liberalismo radical e individualista, que ignora la concepción positiva de la libertad y las exigencias de justicia social y de solidaridad que de ésta se derivan, ni por una identidad comunal particular, como ocurre con el nacionalismo, que ignora la prioridad ontológica del ser humano sobre la colectividad y sacrifica derechos fundamentales en aras de los pretendidos derechos colectivos de la nación.

La respuesta al dilema entre liberalismo individualista y nacionalismo colectivista, que niegan la ciudadanía democrática está en la construcción de una comunidad política que se base y, a la vez, que posibilite el desarrollo de la ciudadanía democrática ${ }^{70}$. Como nos ocurría con la amenaza del capitalismo, tampoco aquí es fácil encontrar la fórmula concreta que materialice dicho proyecto democrático de comunidad política. Autores como Rousseau o Kant, cuando son leídos sin simplificaciones

68 Véase W. Kymlicka. «Derechos individuales y derechos de grupo en la democracia liberal». Isegoría. N. ${ }^{\circ} 14$. 1996.; D. VELASCO. «El reto de los fundamentalismo religiosos y políticos», en Pensamiento político contemporáneo. Universidad de Deusto. 1997. pp. 399-435; «Etica, paz y autodeterminación en Euskadi: perspectivas ético-cristianas», en Razones contra la violencia, vol. I. Bakeaz. Bilbao, 1998. pp. 133-158.

${ }^{69} \mathrm{La}$ denominada por los nacionalistas «democracia vasca», que suele asociarse a una historia manipulada convertida en tradición, en la que el municipalismo premoderno servirá de referente democrático y de argumento deslegitimador de la democracia moderna, liberal e individualista. Como dice A. Elorza, la «democracia vasca» es un instrumento para negar la «democratización de Euskadi». Fórmulas municipalistas, como Udalbitza o el censo vasco, rezumarían el espíritu premoderno de la democracia vasca. En efecto, tal como la definen autoridades canónicas del nacionalismo vasco, como Engracio de Aranzadi (Kizkitza), Sabino Arana o J. de Ariztimuño (sacerdote que escribe en 1935 un libro titulado La democracia vasca, orientado a combatir la «democracia plebeya, descreída y revolucionaria» de tradición liberal e individualista), la democracia vasca municipalista, que distingue entre moradores y vecinos, se niega a abrir las puertas a extraños y a incorporarlos al pueblo, ya que esto equivaldría a destruir a Euzkadi. Véase A. ElorZA. «La democracia vasca». El País, 16/V/2000.

70 R. BEINERT. «Liberalismo, nacionalismo, ciudadanía: tres modelos de comunidad política». Revista Internacional de Filosofía política. N. ${ }^{\circ} 10.1997$. 
indebidas, muestran la complejidad y aporías que lleva consigo la construcción de una verdadera comunidad política. En cualquier caso, si no queremos renunciar a la mejor herencia de nuestra tradición moderna, deberíamos hacer nuestra la posición que mantiene R. Beinert: «Como dice uno de los matones fascistas de la película My Beautiful Launderette, "uno tiene que pertenecer a algo". Extrapolando de la película, esta afirmación sobre la necesidad de pertenencia puede interpretarse de dos maneras: o bien el fascismo es una expresión particularmente maligna de una necesidad humana de pertenencia que en sí misma es benigna, o bien hay una especie de fascismo latente en toda inclinación hacia la pertenencia a un grupo: Me resulta imposible descartar la parte de verdad que existe en la segunda interpretación. Una vez. más, dada la elección entre el liberalismo alienante y el mal latente en todo nacionalismo totalmente consistente, mi respuesta es que debe haber una tercera opción $\gg^{71}$.

Responder adecuadamente a los problemas de identidad en nuestras sociedades exige una tarea de ingeniería constitucional, que no es fácil llevar a la práctica, pero, no creo que sea sólo, ni fundamentalmente, un problema de formas y procedimientos políticos. Una vez más, se trata de que los seres humanos seamos capaces de alcanzar una comprensión esclarecida de la situación, que nos permita, a su vez, un control cognitivo de la misma para resolver responsablemente los problemas que se planteen con plena autonomía democrática.

\subsection{El control y la manipulación de la información, del conocimiento y de la opinión pública. Papel de los Medios de Comunicación}

Si uno de los rasgos definitorios de las sociedades democráticas era el que la ciudadanía pudiera tener una comprensión esclarecida de los problemas, para poder decidir responsablemente y lograr, así, un control efectivo de la agenda, el control y la manipulación de la información y del conocimiento es una de las principales fuentes de nautonomía en nuestras sociedades, que algunos definen, precisamente, como «sociedades de la información». El papel de los Medios de comunicación de masas es decisivo en este tema. Por eso, es imprescindible, si queremos profundizar en la democracia, abordarlo coherentemente.

Ya hemos abordado la posible solución técnica al problema de la deliberación democrática, al tratar de la teledemocracia o del sondeo deliberativo. Pero, en mi opinión, no se trata, una vez más, de ver si

71 R. BeIneRT. Ibid., p. 18. 
técnicamente tenemos soluciones a problemas que no son fundamentalmente técnicos. Si el problema es el de la calidad de la información o, como dice Sartori, de lograr conocimiento, que «consiste en la capacidad no sólo de comprender un problema, sino también de buscar maneras de resolverlo. Eso es control cognitivo... Si una persona está interesada en la cognición, el conocimiento cognitivo, el control cognitivo, entonces lo primero que hará será evitar un exceso de información. En cuanto a la democracia electrónica, mi argumentación es precisamente que cuanta más responsabilidad en la toma de decisiones y más poder de decisión se dé al ciudadano, más hay que mejorar al ciudadano, porque, de otro modo, perderemos la carrera. Y precisamente esto es lo que está ocurriendo: estamos dando más poder a ciudadanos menos informados, menos competentes $y$, en realidad, menos ciudadanos. Los llamo "hipnociudadanos" o "subciudadanos" $\gg^{72}$.

Se trata, pues, de crear, como dice Dahl, la «masa crítica» de ciudadanas y ciudadanos bien informados, lo bastante numerosa y activa como para establecer y afianzar el proceso democrático y, para ello, que sea, además, representativa, de verdad. La fórmula que propone y que ya hemos visto es la del «minipopulus».

Sabemos que el papel de los medios de comunicación es decisivo para crear ese «público atento», ya que en sus manos está tanto el proporcionar información, como posibilitar la creación de una opinión pública libre y responsable, capaz de escapar al control del poder y capaz, además, de controlarlo. Por eso, los medios de comunicación han sido un importante objeto de análisis y de constantes críticas por parte de relevantes analistas sociales, incluso por analistas norteamericanos que, a pesar de ser optimistas respecto a su papel como creadores de cultura de masas y de una mayor nivelación social, han denunciado, por ejemplo, el ser vehículos del deterioro del gusto estético ${ }^{73}$. Pero han sido, sobre todo, los representantes de la Escuela de Frankfurt quienes han hecho una crítica más radical de los medios de comunicación social,

72 G. SARTORI. «El futuro de la democracia», en Claves... op. cit., p. 8. Sartori se queja del predominio creciente de la televisión y su difusión de lo que el llama subinformación y desinformación. «Exactamente, lo que no deberíamos desear y que no ayuda en modo alguno a la democracia. Subinformación significa información insuficiente; y desinformación, información distorsionada. En términos analíticos, la diferencia es clara; en la práctica, se solapa». Ibid., p. 7. Véase, también, su obra Homo videns. La sociedad teledirigida, Taurus. Madrid. 1998.

73 P. F. Lazarsfeld y R.K. Merton, «Los medios de comunicación de masas, el gusto popular y la acción social organizada», en D. BELL et alii. Industria cultural y sociedad de masas. Monte Avila edit. Caracas, 1969, pp. 251-258. 
tanto desde el punto de vista estético, como político. El carácter manipulador de la industria cultural sobre la democracia de masas se refleja en que reproduce y legitima el sistema capitalista vigente cumpliendo las funciones de distracción, diversión, manipulación, represión, estupidización o cosificación. La industria cultural manipula a un consumidor que siempre es objeto pasivo, cuyas necesidades son producidas, guiadas, manipuladas, ya que no debe trabajar con la propia cabeza: toda conexión lógica que requiera esfuerzo intelectual es cuidadosamente evitada ${ }^{74}$.

Los medios de comunicación son, pues, los instrumentos de la dominación burguesa.

Como en otros ámbitos de la realidad, el análisis más adecuado de lo que los medios de comunicación y la cultura popular son, y la función que cumplen, exige una aproximación más critica que la de los sociólogos norteamericanos y más optimista que la de los frankfurtianos. La cultura popular es, a la vez, una cultura dominada y una cultura emancipadora, dependiendo de cómo se hagan los procesos de comunicación cultural. No todo lo que hacen los sujetos que tienen poder hegemónico a través de los medios se convierte en cauce reproductor del sistema. Como decía Gramsci, la hegemonía es un proceso que se hace, deshace y rehace continuamente. A este modelo gramsciano de hegemonía corresponde un concepto de circulación cultural, ya que no es posible un desde arriba que no implique un desde abajo. Así, se trata de construir un nuevo modelo de comunicación en el que los medios de comunicación no son sólo instrumentos o medios, sino que se convierten en «mediaciones». La mediación trabaja recíprocamente entre el emisor y el receptor. Se trata, pues de resaltar el papel activo del consumidor que, con cada producto que recibe, se convierte en un «consumidor productivo», también, en un «productor de sentido». El ejemplo es el del lector de un texto que saca de él la significación que más le interesa (vgr: serie Dallas o figura de Madonna), elige la significación que más le interesa (anti-capitalista o pro-capitalista), dependiendo de las condiciones sociales en las que vive ${ }^{75}$.

Ante el fenómeno denunciado de manipulación y control de la información y del conocimiento que, en nuestro mundo, adquiere unas

\footnotetext{
74 Véase T.W. Adorno. Televisión y cultura de masas, Endecor, Córdoba, Argentina, 1966; Crítica cultural y sociedad. Ariel, Barcelona, 1969; AdORNO y HorkHEIMER, «La industria cultural», en D. BELl et alii, op. cit.

75 Véase J. Fiske. Understanding Popular Culture. Routledge. London and New York. 1989; J. MARTín BARBero. De los medios a las mediaciones. Cultura, comunicación y hegemonía. Ed. Gustavo Gili, Barcelona, 1987.
} 
proporciones dramáticas ${ }^{76}$, no debemos dejar de creer en la capacidad intelectual de los ciudadanos/as para dejar de ser objeto pasivo del conocimiento y para convertirse en sujeto activo y crítico del mismo. También en este ámbito, se trata de dejar de ser los meros «consumidores» de la sociedad de la información, para convertirnos en los ciudadanos creadores de un control cognitivo de la misma. Se trata de crear estrategias de resistencia, convirtiendo los nuevos medios de comunicación en mediaciones capaces de cuestionar el sistema hegemónico y sus legitimaciones. Debemos aprender de la historia de la democracia representativa la lección ya expuesta, Debemos invertir el proceso histórico y sustituir al consumidor siempre satisfecho-insatisfecho y, por tanto, siempre necesitado de más consumo, por el ciudadano exigente y crítico.

\section{La ciudadanía democrática, el objetivo de la comunidad política democrática}

En primer lugar, debemos recuperar el sentido más genuino de la ciudadanía revolucionaria, la que se da en un nuevo mundo en el que el «honor» cede su puesto a la «dignidad». El honor es un bien «posicional» que, como decía Montesquieu, por naturaleza pide preferencias y distinciones. La dignidad, por el contrario, atribuye ciertas cualidades a todo ser humano, entre las que sobresale la libertad, que él tiene que saber afirmar, si no quiere ser indigno de su condición humana. Pero debe hacerlo, no desde una actitud de individualismo posesivo, sino compartiendo su ciudadanía con los demás, los iguales, ejerciendo con ellos la libre deliberación y decidiendo juntos lo que se cree que es mejor para todos.

La ciudadanía democrática debe superar la perversión de este proyecto moderno causada por un capitalismo liberal, desigualitario y excluyente, que ha convertido la ciudadanía en un proyecto elitista, que sólo han podido realizar quienes han gozado del estatuto de «propietarios» $\mathrm{O}$

${ }^{76}$ Los grandes grupos mediáticos están siendo controlados por oligacracias cada vez más concentradas y poderosas, que buscan, en primer lugar, el beneficio económico y la influencia sobre los demás poderes. No ha faltado quien ha dicho que ya no es «el cuarto poder» sino el «primero de los poderes». Véase Temas para el debate, n. ${ }^{\circ} 67$, junio 2000. En la que los expertos llaman «democracia de audiencia» (Manin) o «mediática» (Minc) la manipulación de los medios está logrando pervertir la «representación política» en su aspecto nuclear: la capacidad de los ciudadanos para elegir a los mejores y, despues, exigirles responsabilidades. Además, los estudios realizados sobre el impacto que han tenido los nuevos medios de comunicación, como Internet, han concluido que, lejos de servir para una mayor igualación entre pobres y ricos o para un mejor control del poder, han generado mayor distancia entre pobres y ricos y mayor control y manipulación de la información. 
de «capacitados» para ser, con pleno derecho, sujetos políticos. El sistema capitalista ha consagrado una nueva forma de «honor» censitario, que sólo se ha adjudicado a quienes la Providencia y la historia han destinado a tener la «propiedad, el saber y el poder», y que ha impedido a la mayoría de los seres humanos el afirmar su propia dignidad. Es más, una de las ideologías que mejor y más han legitimado dicho sistema capitalista, como ha sido el «liberalismo doctrinario», ha condenado a los pobres a una doble «indignidad»: la que han tenido por no alcanzar el «honor» de ser elegidos por el destino (la providencia divina o la historia) para ser ricos y la indignidad de no ser humanos con dignidad. La culpa, obviamente, es de los pobres que no han hecho méritos para salir de su pobreza ni se han regenerado de su condición de ignorantes e incapaces. Recuperar la ciudadanía democrática exige cuestionar de raíz esta forma de entender y de organizar la sociedad. El capitalismo es incompatible con la ciudadanía democrática, porque ésta es una ciudadanía social.

Ya hemos hablado antes de la falacia del discurso democrático neoliberal. Todo lo dicho, hay que subrayarlo frente al «capitalismo mutante del siglo XXI» ${ }^{77}$. Para lograr una ciudadanía democrática hay que combatir la desigualdad y el camino no puede ser el que profundiza en ella. A la luz de la igualdad, no sólo de oportunidades, sino también de resultados, hay que valorar las actuales «vías», que se llaman progresistas, como es el caso de la «tercera vía». Hay que apostar por recuperar el valor irrenunciable de la «justicia social» y, cuando no luchemos lo suficiente por lograrlo, al menos, no debemos perder también el pudor de reconocernos indignos por ello. Debemos educarnos en y para la solidaridad. Debemos recuperar la preocupación por el Bien común: no sólo por el Bien del Común, ni siquiera sólo por la «Comunidad en el bien», sino, sobre todo, por el «espíritu de comunión» que posibilite construir de verdad «bien común». Esto es especialmente relevante, en momentos como el actual en que la definición del «bien general» se hace en clave «desideologizada», confundiéndolo con la neutralidad, la eficiencia y la eficacia, conceptos claves de los enemigos de la democracia social.

En sociedades complejas, pluralistas y seculares, el único proyecto de comunidad política compatible con el principio de autonomía democrática

77 Véase el cuaderno de Luis DE SEBASTIÁN «Capitalismo y Democracia en el siglo XXI», que acaba de editar Cristianismo y Justicia. N. ${ }^{\circ}$ 99. junio 2000. La tesis de Sebastián es que el capitalismo va mutando hacia una forma peculiar de socialismo privado, ya que la organización de la producción es planificada, pero la propiedad de los medios de producción es privada. La respuesta a este capitalismo tiene que venir de la recuperación de la igualdad entre todos los seres humanos, el valor más olvidado de la Modernidad; véase asimismo el artículo de G. Soros. «Capitalismo frente a democracia». El País, 15/VII/2000. 
es el que permite integrar las diferentes identidades particulares en una forma de pertenencia común, como es la de la ciudadanía democrática. La ciudadanía democrática es una ciudadanía «cívica», que iguala a los ciudadanos y las ciudadanas desde una forma de identidad y de pertenencia que todos ellos pueden compartir, en igualdad de condiciones, sin discriminaciones ni privilegios originados por imperativos de pertenencia particularistas y excluyentes. Se trata de construir una ciudadanía que sea fruto de la «unidad de convergencia» (no unidad de intimidad en la comunión comunitaria), que, como ya hemos dicho, posibilite «el lugar común de los desarraigados» de todo tipo, incluidos, los carentes de nacionalidad, los extranjeros, los pobres y los condenados de la tierra. Para lograrlo, hay que crear una «cultura política común», que genere una conciencia de solidaridad entre todos. Así como el estado-nación democrático, con las limitaciones y carencias ya conocidas, sirvió para crear una conciencia nacional (a través de la escuela y del ejército, y a través de los medios de comunicación), que se plasmó en una «constitución», con su parte dogmática (principios y valores) y su parte institucional (instituciones y procedimientos), también ahora hay que posibilitar la creación de una «cultura política común», en la que se articulen los valores y principios democráticos (sobre todo, el núcleo básico de la democracia cosmopolita) con las instituciones y procedimientos que los hagan viables y plausibles. Creo que, en la construcción europea, se ha descuidado este objetivo y sigue primando una cultura particularista. Urge, como dice Bourdieu, crear una red de partidos, asociaciones, instituciones y partidos políticos europeos, que deliberen y gestionen con mentalidad europea. La disputa sobre el estudio de las humanidades y de la historia, me parece que tiene una trascendencia que no debería hipotecarse a los intereses partidistas. En mi opinión, el problema del nacionalismo radical vasco no tendrá solución mientras «no se sustituya la "formación del espíritu nacional" por la formación del espíritu ciudadano» ${ }^{78}$. Una formación ecuménica, abierta, laica (en oposición a dogmática), y tolerante, capaz de convivir democráticamente con la pluralidad y la diferencia.

En sociedades de la información y con recursos capaces de hacer llegar a todos los rincones del planeta el conocimiento para que los seres humanos logremos un control cognitivo democrático de los procesos de transformación que está teniendo nuestro mundo, hay que apostar por la educación. Si en la Atenas de Pericles, la educación era la «gran cosa», hoy sigue siéndolo con más razón. Si la información es poder, para quien la sabe convertir en control cognitivo de la situación que le

78 Véase A. ARTETA. «Jaque mate». El País, 28/VI/2000. 
toca vivir, es claro que es imprescindible una educación que forme ciudadanos y ciudadanas informados y competentes, a la vez que adultos y responsables, porque hacen un uso crítico de su razón y de su libertad.

La educación como un derecho básico, que permite desarrollar las capacidades del ser humano, obliga a la sociedad a proporcionar los recursos disponibles para alcanzar dicho objetivo. La universalidad de dicho derecho sólo se logrará cuando todos y cada uno de los ciudadanos y ciudadanas se eduquen de forma históricamente suficiente. A pesar de lo que diga Fukujama, no estamos «al final de la historia». Al «altruismo particular», le ha sucedido un «egoísmo universal», pero tenemos que andar todavía mucho camino para alcanzar el «momento» del «altruismo universal» (muchas de las solidaridades presentadas como «universales» siguen siendo excluyentes). La «figura» hegeliana del «reconocimiento» sigue siendo el reto de una educación a la altura de las exigencias de nuestro tiempo.

Concluyo con un cuento casídico, que recoge bien todo lo que decimos: «Un viejo rabino preguntó una vez a sus alumnos, cómo se sabe la hora en que la noche ha terminado y el día ha comenzado. ¿Será, dijo uno de los alumnos, cuando uno puede distinguir a lo lejos un perro de una oveja? No, contestó el rabino. ¿Será, dijo otro, cuando puedo distinguir a lo lejos un almendro de un duraznero? Tampoco, contestó el rabino. ¿Cómo lo sabemos entonces?, preguntaron los alumnos. Lo sabremos, dijo el rabino, cuando, al mirar a cualquier rostro humano, reconozcas a tu hermano o tu hermana. Mientras tanto, seguiremos estando en la noche» ${ }^{79}$.

79 Citado por TugenghadT, op. cit. La referencia a este cuento casídico y a su exigencia de reconocimiento del rostro del hermano o de la hermana en cualquier rostro humano, me obliga a traer a colación, aunque sólo sea para mostrar la parcialidad de la reflexión que aquí concluyo, la necesidad de enriquecer esta reflexión sobre la política, en general, y sobre la construcción democrática, en particular, desde una tradición diferente y complementaria a la ilustrada. Me refiero a la tradición judeocristiana de la «razón anamnética», que algunos autores judíos importantes supieron hacer significativa a principios de siglo, anunciando la catástrofe a la que nos llevaba una razón moderna occidental carente de dimensión ética. El holocausto judío les haría testigos trágicos de sus predicciones y les otorgaba argumentos sobrados para cuestionar dicha racionalidad occidental y la misma matriz de la tradición judeocristiana, tal como la reformuló el protestantismo ascético, del que nos ha dejado buena relación la obra de Weber. La recuperación de la tradición judeocristiana de la razón anamnética nos posibilitaría generar el clima de solidaridad y de reconocimiento humanos que, como hemos visto, necesitamos para profundizar la democracia. En efecto, la constitución del sujeto moral, la adecuada formulación de la teoría de la justicia, la recuperación del sentido de la política y de las verdaderas motivaciones de la acción política, cuestiones todas ellas claves para el tema que nos ocupa, pueden encontrar en dicha tradición una fuente inagotable de inspiración y de recursos morales y políticos. Remito al lector a autores como Benjamín, Levinas, Cohen... Entre nosotros, ha sido REYEs MATE uno de los que más ha trabajado en la recuperación de esta tradición. Véase su breve, pero significativo artículo, «Religión y política. Por un nuevo planteamiento», en Iglesia Viva. ‥ ${ }^{\circ}$ 178/179. 1995. pp. 429-448. 